\title{
Pharmacological Intervention to Modulate HDL: What Do We Target?
}

\author{
Nicholas J. Woudberg', Sarah Pedretti ${ }^{1,2}$, Sandrine Lecour', Rainer Schulz ${ }^{3}$, \\ Nicolas Vuilleumier ${ }^{4}$, Richard W. James ${ }^{2}$ and Miguel A. Frias ${ }^{2,4 *}$
}

\begin{abstract}
${ }^{1}$ Hatter Institute for Cardiovascular Research in Africa and South African Medical Research Council Inter-University Cape Heart Group, Department of Medicine, Faculty of Health Sciences, University of Cape Town, Cape Town, South Africa, ${ }^{2}$ Division of Endocrinology, Diabetes, Hypertension and Nutrition, Department of Internal Medicine Specialities, Faculty of Medicine, University of Geneva, Geneva, Switzerland, ${ }^{3}$ Institute of Physiology, Justus Liebig University Giessen, Giessen, Germany, ${ }^{4}$ Division of Laboratory Medicine, Department of Genetics and Laboratory Medicine, Geneva University Hospitals, Geneva, Switzerland
\end{abstract}

The cholesterol concentrations of low-density lipoprotein (LDL) and high-density lipoprotein (HDL) have traditionally served as risk factors for cardiovascular disease. As such, novel therapeutic interventions aiming to raise HDL cholesterol have been tested in the clinical setting. However, most trials led to a significant increase in HDL cholesterol with no improvement in cardiovascular events. The complexity of the HDL particle, which exerts multiple physiological functions and is comprised of a number of subclasses, has raised the question as to whether there should be more focus on HDL subclass and function rather than cholesterol quantity. We review current data regarding HDL subclasses and subclass-specific functionality and highlight how current lipid modifying drugs such as statins, cholesteryl ester transfer protein inhibitors, fibrates and niacin often increase cholesterol concentrations of specific HDL subclasses. In addition this review sets out arguments suggesting that the HDL3 subclass may provide better protective effects than HDL2.

Keywords: HDL, pharmaceutical intervention, HDL functionality, HDL subclass, cardiovascular disease

\section{INTRODUCTION}

Cardiovascular disease (CVD) are the leading cause of death globally (GBD 2013 Mortality and Causes of Death Collaborators, 2015). It is predicted that the number of deaths from CVD will increase to 23.3 million by 2030 (Mathers and Loncar, 2006). Blood lipids have traditionally served as accurate risk factors for cardiovascular events. Increases in low-density lipoprotein (LDL) cholesterol and decreases in high-density lipoprotein (HDL) cholesterol rise cardiovascular risk (Gordon et al., 1977; Barter and Rye, 1996; Jeppesen et al., 2000; Kontush et al., 2003). The protective effect of HDL has been primarily attributed to reverse cholesterol transport (RCT). This process removes cholesterol from macrophages and other cells residing in the blood vessel wall and exports it to the liver, thus reducing LDL contribution to the development of atherosclerotic plaques and therefore reducing the risk of an

Abbreviations: ABCA1 and ABCG1, ATP binding cassette A1 and G1; ApoAI, apolipoprotein AI; CAD, coronary artery disease; CETP, cholesterylester transfer protein; COX-2, cyclooxygenase-2; CVD, cardiovascular disease; HbA1c, glycated hemoglobin; HDL-C, HDL cholesterol; HMG CoA, 3-hydroxyl-3-methyl-glutaryl-coenzyme A; ICAM, intercellular cell adhesion molecule; LCAT, lecithin-cholesterol acyltransferase; LDL-C, LDL cholesterol; PAF, platelet activating factor; PAF$\mathrm{AH}$, platelet activating factor acetylhydrolase; PGI2, prostacyclin; PON1, paraoxonase; RCT, reverse cholesterol transport; rHDL, reconstituted HDL; S1P, sphingosine-1-phosphate; SAA, serum amyloid A; VCAM, vascular cell adhesion molecule. 
ischemic event (Barter and Rye, 1996; Yu X.H. et al., 2013). HDL had long been considered as a primary therapeutic target for lowering the risk of atherosclerotic disease. Despite the development of effective HDL-raising drugs, large-scale clinical trials showed disappointing results with no significant reduction of clinical cardiovascular events (Boden et al., 2011; Schwartz et al., 2012). Whilst this may indicate that targeting an increase in HDL cholesterol (HDL-C) should be reconsidered we argue that this, in fact, underlines not only the complexity of HDL particle metabolism but also the complexity of HDL structure, composition and function. It also suggests that focusing on improving HDL quality rather than just increasing HDL quantity may be the next target for future therapies. Historically, HDL particles have been subdivided in several subclasses according to their density, but these subdivisions also reflect differences in their functional properties as defined by the different proteins and lipids associated with the subclasses.

The aim of this review is to consider the different HDL subclasses as one possible target for more efficient cardiac protection. The different HDL subclasses will be described and evidence regarding the superiority of particular HDL subclasses, undoubtedly reflecting their composition for improved cardioprotection will be discussed. Finally, this review will attempt to explain the failures observed in past and current HDL therapies for CVD.

\section{HDL: STRUCTURE, COMPOSITION, AND FUNCTION}

There are presently two major, interlinked objectives of research into HDL. One is to understand the mechanisms by which HDL protects against CVD (functionality), and how these mechanisms are compromised in different pathological states. The second objective is clinical and aims to identify HDL parameters that more accurately estimate cardiovascular risk as well as providing diagnostic tools applicable in the clinical laboratory. The following section will review various characteristics of HDL with these two objectives in mind.

\section{DEFINITION}

Of the major lipoprotein classes, HDL are defined by their high protein:lipid ratio and the predominant presence of apolipoprotein (apo) AI, which accounts for approximately 70\% of the total protein content of the lipoprotein and 30-40\% of total protein-lipid content (Gillard et al., 2009). ApoAII is the other major HDL apolipoprotein, accounting for 10-15\% of total protein content. HDL are the most heterogeneous of the lipoproteins, varying in buoyant density, electrophoretic mobility, size, protein and lipid composition (Figure 1). More than 80 proteins and 150 lipids have been shown to be associated with HDL particle. Thus, it is highly unlikely that each lipoprotein particle carries the same complement of protein or lipid components. Reflecting, in part, metabolic processing within the plasma compartment. Lipid poor apoAI

\section{HDL particle heterogeneity}

\section{Discoid (nascent)

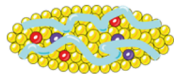 \\ Pre- $\beta-1$ \\ Spherical

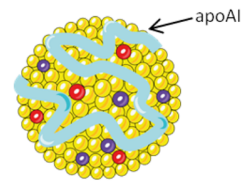 \\ HDL2 (2a, 2b) \\ protein:lipid ratio 40:60 $100 \AA ̊$ and $350 \mathrm{kDa}$

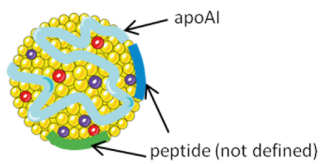 \\ $\operatorname{HDL} 3(3 a, 3 b, 3 c)$ \\ protein:lipid ratio 55:45 \\ $75 \AA ̊$ and $175 \mathrm{kDa}$ \\ HDL particle composition \\ Apolipoproteins : \\ Al, All, Cl, CII, CIII, D, E, F, H, J, L, M Enzymes : \\ PON1, PON3, LCAT, PLA2, PAF-AH \\ Other : \\ CETP, PLTP, HRP, SAA \\ Associated lipids \\ PL, TG, steroids, SL, FA, S1P}

FIGURE 1 | Schematic representation of HDL heterogeneity. PON, paraoxonase; LCAT, lecithin-cholesterol acyltransferase; PLA2, phospholipase A2; PAF-AH, platelet activating factor acetylhydrolase; CETP, cholesterol ester transfer protein; PLTP, phospholipid transfer protein; HRP, haptoglobin related protein; SAA, serum amyloid Al and All; PLs, phospholipids; TG, triglyceride; SLs, sphingolipids; FA, fatty acid; S1P, sphingosine-1-phosphate.

(of hepatic or intestinal origin) acquires increasing quantities of phospholipids and cholesterol, maturing through nascent discoidal HDL (pre $\beta$-1 HDL) to form spherical HDL (Figure 1) (Rye and Barter, 2014). The latter arises from esterification of acquired cholesterol by lecithin-cholesterol acyltransferase (LCAT), and absorption of triglycerides that create a hydrophobic core, which must be shielded from the aqueous environment by amphipathic phospholipids and proteins. In contrast to other plasma lipoproteins, where the whole particle is eliminated, the cholesterol component alone of spherical HDL is transferred to the hepatocyte. The residual, lipid poor apoAI becomes available to recycle through the maturation process, before eventual renal excretion (Rye and Barter, 2014). These factors add several levels of complexity to attempts either to correlate serum HDL with cardiovascular risk, or define the functions of the lipoprotein.

In terms of clinical relevance, it is presently the cholesterol component of HDL that is of primary importance. A wide range of retrospective and prospective epidemiological studies have consistently demonstrated its inverse correlation with the incidence of atherosclerotic disease (Gordon et al., 1977; Assmann et al., 1996; Barter and Rye, 1996; Goldbourt et al., 1997). It is thus still incorporated in clinical guidelines as one of the primary parameters for assessing cardiovascular risk (Piepoli et al., 2016). Perhaps surprisingly, cholesterol is a relatively minor component of HDL. It represents $15 \%$ by weight. Unfortunately, 
recent clinical trials that attempted to reduce cardiovascular risk by pharmacologically increasing the cholesterol content of HDL have been unsuccessful (Kühnast et al., 2015). This has provoked a re-think of the mechanisms by which HDL may protect the vascular system, and given greater weight to the heterogeneity of HDL subtypes as a factor in the multiple functions of the lipoprotein.

\section{HDL FRACTIONATION AND ISOLATION}

Several of the properties of HDL outlined above have been exploited to fractionate HDL subclasses. These include HDL electrophoretic mobility which utilizes non-denaturing, twodimensional gel electrophoresis to fractionate of HDL revealing the presence of the subclasses (Asztalos et al., 2011). These can be visualized and quantified by appropriate staining techniques. However, the procedure does not lend itself to isolation of HDL subclasses.

HDL buoyant density techniques exploit the protein/lipid ratio of lipoproteins to allow sequential lipoprotein flotation by ultracentrifugation in a high salt medium (Lindgren et al., 1972). The major lipoprotein classes can be separated due to their differing protein:lipid ratios and types of lipid. Ultracentrifugation is the principal procedure used to isolate HDL subfractions, predominantly HDL2 and HDL3. These can be further divided by more sophisticated centrifugation procedures into subclasses HDL2a and b and HDL3a, b, c, as illustrated in Figure 1 (Rosenson et al., 2011).

Whilst numerous proteins are associated with HDL, their concentrations are minor compared to that of apoAI. Alaupovic (2003) suggested that such protein heterogeneity could be exploited to define discrete HDL subclasses. As the proteins define HDL function, isolation via these components could give rise to subtypes of greater functional homogeneity. The procedure requires monospecific antibodies that can be used to prepare affinity absorption columns. One major drawback is that the acidic elution conditions can adversely affect the function of the isolated subclasses.

\section{HDL SUBCLASS STRUCTURE AND FUNCTION}

\section{Pre $\beta$-1 HDL}

These are structurally the simplest form of HDL. They consist of 1-2 molecules of apoAI with a layer of phospholipid molecules and trace amounts of cholesterol. Pre $\beta-1$ HDL accounts for only $5-6 \%$ of plasma HDL, in part because their high capacity to absorb phospholipids and cholesterol rapidly converts them to other HDL species. Pre $\beta-1$ HDL are hypothesized to be the first link in the chain of events preventing the development of atherosclerotic plaque, because of their function is to avidly remove cholesterol (the non-esterified form) and phospholipids from cells via binding to the cell surface, ATP binding cassette A1 and G1 (ABCA1 and ABCG1) transporter protein. Studies supporting this function have established that the plasma content of pre $\beta$ - 1 is a major determinant of the rates of cholesterol efflux from macrophages (de la Llera-Moya et al., 2010).

\section{HDL Subclasses 2 and 3}

Spherical HDL is a spectrum of lipoprotein particles that covers the density range $d 1.063-1.21 \mathrm{~g} / \mathrm{ml}$. HDL3 occupies the density range $d 1.125-1.21 \mathrm{~g} / \mathrm{ml}$. It is protein enriched (mean protein:lipid ratio 55:45 by weight), with a mean particle diameter of $75 \AA$ and a mean molecular weight of $175 \mathrm{kDa}$. HDL 2 occupies the lower density range of the spectrum $(d 1.063-1.125 \mathrm{~g} / \mathrm{ml})$, reflecting lipid enrichment (protein:lipid ratio 40:60) compared to HDL3. Its mean diameter and molecular weight (100 ̊ and $350 \mathrm{kDa}$, respectively) are correspondingly greater than HDL3 (Chapman, 1986) (Figure 1). HDL3 is the predominant HDL subclass. Women have significantly higher concentrations of HDL, both for HDL3 ( 25\%) and notably for HDL2 (two to threefold higher). ApoAI and AII are major structural peptides of both subclasses. However, HDL3 is enriched in apoAII compared to HDL2 (a fivefold lower apoAI:AII concentration ratio than in HDL3).

With respect to the major lipid components of the subclasses (esterified and free cholesterol, phospholipids, triglycerides) there is no marked difference in concentrations between HDL2 and HDL3. Nevertheless, the relative concentrations (\% total mass) of esterified cholesterol and phospholipids are greater in the HDL2 subclass, reflecting increased lipid content. However, increased HDL3 concentration implies that with respect to serum concentrations, HDL-associated cholesterol is present in greater concentrations in HDL3, notably for men.

\section{HDL Subclass Definition According to Protein Content}

Proteomics has allowed for identification of differences in the protein profiles of HDL2 and HDL3 (Davidson et al., 2009). As noted above, apoAII is more present in HDL3 compared to HDL2. A second feature, which may impact on function, is the enrichment of minor proteins in the HDL3 subclass compared to HDL2 (Table 1). Such studies are also revealing clusters of proteins within HDL that have common functions

TABLE 1 | Relative distribution of peptides between HDL2 and HDL3.

\begin{tabular}{l} 
Preferentially in HDL3 \\
\hline Paraoxonase-1 (PON1) \\
Paraoxonase-3 (PON3) \\
Apolipoprotein F \\
Apolipoprotein L-I \\
Apolipoprotein J (clusterin) \\
Apolipoprotein M \\
Apolipoprotein D \\
Apolipoprotein A-IV \\
PAF-acetylhydrolase \\
Serum amyloid Al and All \\
Haptoglobin related protein
\end{tabular}
Preferentially in HDL2 Apolipoprotein $\mathrm{Cl}$ Apolipoprotein Cll Apolipoprotein CIII Apolipoprotein E

Haptoglobin related protein 
linked to particular activities, including complement activation, the innate immune response, oxidative stress and regulation of proteinase activity, through which a number of pathological processes could be influenced (Vaisar et al., 2007; Davidson et al., 2009). For example, paraoxonase (PON)-associated HDL are associated with the anti-coagulant protein S (Moren et al., 2016) and transthyretin (TTR) or prealbumin can be differentially associated in HDL in patients with differing risk of CVD (Cubedo et al., 2012).

\section{HDL and Lipid Content}

In a recent study, Serna et al. (2015) identified more than 150 different lipids in HDL particles. Quantitatively, phospholipids (phosphatidylcholine and sphingomyelin) are the main constituents of the HDL lipidome (40-60\%), followed by esterified cholesterol (30-40\%), triglycerides (5-12\%), and free cholesterol (5-10\%) (Wiesner et al., 2009). Changes in lipid composition can occur and may alter the atheroprotective capacities of HDL (Salazar et al., 2015). Little work has been undertaken on the distribution of the minor lipid components between the subclasses. It has been reported that in general sphingolipids are less enriched in HDL3, which, together with a lower free cholesterol content (also present in the outer lipid layer of lipoproteins) may impact on surface lipid fluidity and thus lipoprotein function (Kontush et al., 2013). In contrast, sphingosine-1-phosphate (S1P), a particularly bioactive lipid, is preferentially associated with HDL3 (Kontush et al., 2007; Serban et al., 2014). S1P is generated intracellularly from sphingomyelin and is transported to extracellular environment where it binds to HDL (Mitra et al., 2006). The diverse atheroprotective functions of HDL and the mechanisms by which these effects are achieved have been in many cases linked to the S1P content of HDL. These include, preventing ischemic injury (Theilmeier et al., 2006; Frias et al., 2012); reducing cytotoxicity (Kimura et al., 2001; Kontush et al., 2007); inducing prostacyclin release (Liu et al., 2012) and preventing LDL oxidation (Kontush et al., 2007; Rodríguez et al., 2009). In patients with coronary artery disease (CAD), the content of S1P in HDL particle was lower, and could be raised using in vitro S1P loading (Sattler et al., 2010, 2015). This observation was recently extended to patients with coronary in stent restenosis (Jing et al., 2015) and in type 2 diabetic patients (Brinck et al., 2016). In this very recent paper we showed that the content of S1P is inversely correlated with glycated hemoglobin (HbAlc) in type 2 diabetic patients and the concentration of S1P is directly correlated with its cardiac specific anti-apoptotic capacity (Brinck et al., 2016).

Research is now centered on understanding the different activities associated with HDL, how they impact on cardiovascular physiology and pathophysiology beyond lipid transport and how they may contribute to the global cardioprotective effect of lipoprotein. The highly heterogeneous nature of $\mathrm{HDL}$, reflecting the complex metabolic process to which it is subjected in serum, whilst complicating attempts to characterize the lipoprotein, may also provide a framework for compartmentalization of HDL functions. This is one of the intriguing questions that present studies are addressing.

\section{HDL FUNCTIONALITY}

As mentioned above, HDL-C measurement does not reflect its functionality. The complex composition leads to several HDL functions which can be measured by bioassay. Here, are some examples of analysis that could be considered for the measurement of HDL functionality.

\section{HDL and Reverse Cholesterol Transport (RCT)}

The original pathway delineated by Glomset (1968) involves the physiological removal of cholesterol from peripheral tissues and cells and transportation by HDL to the liver for excretion in the bile and feces. RCT prevents the onset of atherosclerotic plaques and lesions which would result from exaggerated uptake by activated macrophages (Yu J. et al., 2013). Macrophage-specific RCT to apoAI is the critical step for RCT and is routinely described as being the main conduit for the atheroprotective actions of HDL (Rader et al., 2009). In addition, recent evidence also suggests that the biogenesis of HDL, mediated by ABCA1, also facilitates the release of microparticles, contributing up to $30 \%$ of apoAI-driven cholesterol efflux (Hafiane and Genest, 2017).

Cholesterol efflux capacity exhibits a robust, inverse relationship with prevalent coronary and peripheral atherosclerosis across human studies (Yvan-Charvet et al., 2007; Out et al., 2008; Tall et al., 2008; Khera et al., 2011; Ishikawa et al., 2015), as well as with incident atherosclerotic cardiovascular events (Rohatgi et al., 2014; Saleheen et al., 2015). Crucially, the findings of Rohatgi et al. (2014) demonstrate how cholesterol efflux capacity was an independent predictor of incident cardiovascular events, and was maintained following adjustment for HDL-C concentrations (Rohatgi et al., 2014). Measurement of cholesterol efflux capacity is currently the most promising assay to define one aspect of HDL functionality. The impact of lipid lowering drugs on cholesterol efflux capacity was recently summarized by Brownell and Rohatgi (2016).

\section{HDL and Antioxidant Function}

High-density lipoprotein prevents accumulation of oxidized LDL which would reduce the structural integrity and function of the endothelium. HDL inhibits metal ion induced oxidation of LDL and lipid peroxidation (Hessler et al., 1979; Parthasarathy et al., 1990; Navab et al., 2000). A key structural component of HDL associated with its antioxidant activity is PON1 which diminishes lipid peroxide formation (Mackness et al., 1991, 1993). PON1 activity is associated with a decrease in the risk of cardiovascular event (Ayub et al., 1999; Ansell et al., 2003; Mackness et al., 2003). In hypertensive patients, however, a recent study concluded that increased hypertensive risk was independently associated with HDL-C and not with PON1 activity (Kunutsor et al., 2017). However, epidemiological studies continue to demonstrate that polymorphisms influence PON1 activity, the most significant being R192Q genotype. HDL from individuals with 192QQ homozygote are the most effective to inhibit LDL oxidation (Durrington et al., 2001; Wheeler et al., 2004). Measuring 
PON1 activity in serum is an attractive means to monitor the antioxidant capacity of HDL.

\section{HDL Anti-inflammatory Function}

In addition to a number of antioxidant effects, HDL also serves as a powerful mediator of the cellular inflammatory and antithrombotic responses. Activated monocytes release inflammatory factors that can induce endothelial dysfunction, characterized by an increase of adhesion molecules expression, such as vascular cell adhesion molecule (VCAM), intercellular cell adhesion molecule (ICAM), and E-selectin (Calabresi et al., 2002; Barter et al., 2004). The ability of HDL to down-regulate the expression of these adhesion molecules has served to evaluate its antiinflammatory capacity (Cockerill et al., 1995; Calabresi et al., 2002; Gomaraschi et al., 2008; Woudberg et al., 2016).

\section{HDL Anti-thrombotic Function}

Platelet activating factor (PAF) is a potent activator of platelets, monocytes, and leukocytes (Stafforini et al., 1987). The metabolism of PAF in the blood is almost completely regulated by the enzyme PAF acethyldrolase (PAF-AH), which is a structural component of both LDL and HDL. The measurement of PAFAH activity associated with HDL may reflect its potential antithrombotic activity (Stafforini et al., 1987).

Another primary anti-thrombotic action of $\mathrm{HDL}$ is activation of prostacyclin (PGI2) release. PGI2 is an arachidonic acidderived lipid mediator and is a powerful inhibitor of platelet activation. PGI2 promotes smooth muscle relaxation and reduces the release of growth factors that promote smooth muscle cell proliferation (Viñals et al., 1999). HDL increases PGI2 release by endothelial cells via at least two mechanisms. These involve HDL cholesteryl esters serving as arachidonic acid donors for PGI2 production by the cyclooxygenase-2 (COX-2) enzyme and by increases in COX-2 expression (Fleisher et al., 1982; Vinals et al., 1997; Cockerill et al., 1999; Escudero et al., 2003; MartínezGonzález et al., 2004). Regarding the mechanism of action, moreover, S1P increases the production of cyclic adenosine monophosphate (cAMP) in smooth muscle cells, which induces PGI2 production by increasing COX-2 expression (Damirin et al., 2005).

In addition, HDL limits vasorelaxation through modulation of endothelial nitric oxide synthase (eNOS). Modulation of eNOS activity by HDL has been demonstrated in both cultured endothelial cell and animal models (Besler et al., 2011). Mechanistically, HDL stimulates eNOS activity through scavenger receptor $\mathrm{B} 1$ (SRB1) and $\mathrm{S} 1 \mathrm{P}$ receptors 1 and 3 (Yuhanna et al., 2001; Nofer et al., 2004; Igarashi et al., 2007). HDL induces Akt phosphorylation, extracellular signal-regulated kinase (erk)1/2 and intracellular calcium ion release, which play roles in a sequence of activation steps leading to phosphorylation of eNOS at Ser-1177 (Mineo and Shaul, 2003; Nofer et al., 2004).

In summary, several assays on HDL functionality may improve the prognosis of future cardiovascular events (O'Neill et al., 2015a). Although HDL functionality measurement may be an approach to evaluate risk of cardiovascular event, most are bioassays. A wide variety in protocols used for similar assays reduces the reproducibility and their assessment is time-consuming, thus making their present use for obtaining rapid diagnostic value limited. Therefore, the use of subclass determination or the enzyme activity may be more practical and faster to use in diagnostic circumstances.

\section{Altered HDL Functionality}

The concept of dysfunctional HDL relates to a total loss of HDL function where the normal anti-atherogenic lipoprotein starts displaying pro-atherogenic properties, often as a result of structural changes (Kontush et al., 2013; Serban et al., 2014; O’Neill et al., 2015b; Rosenson et al., 2016), reviewed by Lüscher et al. (2014). Dysfunctional HDL was first demonstrated during acute phase response in patients following cardiac surgery (Van Lenten et al., 1995) where HDL had a loss in PON1 and PAF-AH activities, combined with a loss in the apoAI content, rendering it pro-inflammatory (Van Lenten et al., 1995). Similarly, during acute phase response, serum amyloid A (SAA), a pro-inflammatory protein, replaces apoAI in HDL structure (Cabana et al., 1996). Binding of SAA to proteoglycans can immobilize HDL in the arterial wall, preventing it from performing anti-atherogenic and anti-inflammatory functions (Lewis et al., 2004; Han et al., 2016). It has been recently shown that increased SAA content in HDL results in increased CVD risk with SAA modifying vascular properties of HDL (Zewinger et al., 2015). Triglyceride enrichment in the HDL core, in patients with CVD and during acute phase response can also cause inhibition of HDL function (Cabana et al., 1996; Brites et al., 2000). Triglyceride content may alter apoAI conformation, limiting access of the central and C-terminal regions to the surface, causing inhibition of apoAI and consequently, HDL functions (Curtiss et al., 2000).

Subsequent to findings from acute phase response, a number of other pathologies and conditions have elucidated the phenomenon of dysfunctional HDL. Dysfunctional HDL is characteristic in patients with $\mathrm{CAD}$, presenting proinflammatory HDL phenotype when compared to controls (Ansell et al., 2003; Besler et al., 2011; Holy et al., 2014; Sattler et al., 2015). In chronic renal disease, the HDL functions are impaired and capacity to promote cholesterol efflux, the antioxidant and anti-inflammatory effects are diminished compared to HDL from control subject (Vaziri, 2015). Recent data suggested the role of carbamylation in this process (Sun et al., 2016). We and others have demonstrated that HDL can become dysfunctional in patients with diabetes mellitus as a result of structural changes including HDL glycation (Nobécourt et al., 2010; Brinck et al., 2016) and a truncated form of apoAI (Cubedo et al., 2015; Estruch et al., 2017). This has also been shown in patients with insulin resistance whilst smoking has been linked with producing dysfunctional HDL subclasses with increased susceptibility to glycation (McMillen et al., 2005; Song et al., 2015). Additionally platelets can modify native HDL, resulting in a dysfunctional and pro-thrombotic form (Blache et al., 2012). Patients with familiar hypercholesterolemia display reduced concentrations of apoAIV and LCAT and a truncated form of apoLI (Cubedo et al., 2016; Badimon et al., 2017). Experimental studies showed that much of the structural modifications and impairment in HDL function are as a result 
of increased LDL cholesterol (LDL-C) concentrations (Vilahur et al., 2015; Padró et al., 2017). HDL dysfunction is a new aspect of HDL metabolism reflecting its complexity and requires further investigation to analyze the effects of disease on HDL function.

\section{WHICH HDL SUBCLASS TO IMPROVE PROTECTIVE CAPACITY?}

Allocating activities to discrete HDL particles appears as an attractive means of compartmentalizing the functional diversity of HDL. It may also refine our understanding of the association of HDL with cardiovascular risk if one considers that particle specific changes, rather than global changes in HDL, are linked to risk. In order to address this point, we will compare below the functional effectiveness and risk prediction capacity of the cholesterol content and relative levels of HDL2 and HDL3.

\section{HDL2 AND HDL3 SUBCLASSES}

Early epidemiological studies describe HDL2 as more accurate risk indicator for CVD. Indeed, myocardial infarction survivors had significant decreases in HDL2 (Brugger et al., 1986), and HDL2 was inversely correlated with coronary heart disease risk (Johansson et al., 1991). A large study of 4594 healthy patients demonstrated that a decrease in HDL2 was associated with increased CVD risk (Musunuru et al., 2009) and patients with acute coronary syndrome displayed decreased levels of HDL2 and increased levels of HDL3 (Tian et al., 2014). These modern studies continue to argue for HDL2 as a risk factor, although discrepancies continue to confound the argument.

In contrast, post hoc analysis of two prospective studies, the IDEAL (Incremental Decrease in End Points through Aggressive Lipid Lowering) trial and the EPIC (European Prospective Investigation into Cancer and Nutrition)-Norfolk case-control study, showed a very high concentration of HDL2 particles, when not accompanied by a correspondingly high level of apoAI containing HDL (i.e., over-enrichment of HDL in cholesterol), may be associated with increased rather than decreased cardiovascular risk (van der Steeg et al., 2008). Kavo et al. (2012) studied HDL from patients who survived a myocardial infarction (MI) at a young age ( $\leq 35$ years) and healthy control subjects and showed that MI patients had reduced pre $\beta-1$ and HDL3 and elevated HDL2 (Kavo et al., 2012). Martin et al. (2014) analyzed the data from two cohorts, the Translational Research Investigating Underlying disparities in acute Myocardial infarction Patient's Health Status (TRIUMPH) and Intermountain Heart Collaborative Study (IHCS), which indicated that HDL3, rather than HDL2 and total cholesterol, was an improved negative predictor of mortality in myocardial infarction patients (Martin et al., 2014). These data are confirmed by the recent results of the secondary analysis of the AIM-HIGH Study which indicate that the levels of HDL3 and no other lipoprotein fractions are predictive of cardiovascular events (Albers et al., 2016). Further, Ditah et al. (2016), showed that smaller HDL particles, quantified by nuclear magnetic resonance, are inversely independently associated with coronary artery calcification and represents a protective subpopulation (Ditah et al., 2016).

It is clear that controversies exist between preclinical and clinical data regarding the beneficial influences of HDL2 and HDL3. However, when considering the biochemical basis for improved protection, it becomes clear that HDL3 may be the better candidate.

The majority of preclinical studies demonstrate stronger beneficial effects of HDL3 compared to HDL2. Early animal studies indicated that in vivo administration of smaller HDL subclasses inhibited the development of atherosclerotic lesions in cholesterol-fed rabbits (Badimon et al., 1989, 1990). Further, an in vitro study, HDL3 inhibited LDL oxidation better than HDL2 (Kontush et al., 2003). Shuhei et al. (2010), evaluated in vitro the kinetics of copper sulfate-induced oxidation of HDL subclasses in human subjects. HDL3 subclass was less prone to oxidation than HDL2. This may be explained by a higher PON1 activity observed in HDL3 (Shuhei et al., 2010). HDL3 also inhibited tumor necrosis factor alpha (TNF- $\alpha$ ) - induced inflammation more effectively than HDL2 (Ashby et al., 1998). HDL3 was functionally superior to HDL2 in all functionality assays including cholesterol efflux capacity, antioxidant, anti-thrombotic, and anti-apoptotic properties (Camont et al., 2013). The results of this study provide the strongest evidence for HDL3 being the functionally superior HDL subclass.

An explanation of the more beneficial effects of HDL3 can be found in its composition (see Table 1). Among the components of HDL3, PON1, apoJ, and S1P that have been shown to be protective, while HDL2 contains apoCIII which has been associated with a higher risk of cardiovascular events (Riwanto et al., 2013). In the next section, we will review evidence that raising-HDL drugs should focus more on increasing HDL3 subpopulation than total HDL-cholesterol.

\section{SELECTIVE HDL SUBCLASS MAY EXPLAIN DISCREPANCIES IN THERAPIES TARGETING AN INCREASE IN HDL}

\section{Statins}

Statins inhibit the hepatic synthesis of cholesterol through inhibition of 3-hydroxyl-3-methyl-glutaryl-coenzyme A (HMG CoA) reductase (Istvan and Deisenhofer, 2001). Statins have the most widespread application of the different lipid lowering agents owing to an active reduction in LDL-C levels (Gotto and Opie, 2005). While the major beneficial effect of statins is attributed to its strong capacity to decrease LDL-C levels, a secondary action shows a small increase (approximately $5-10 \%$ ) 
in HDL-C levels, however, in patients with low HDL-C levels statins treatment did not seem to improve CVD risk (Jafri et al., 2010). Indeed, in patients treated with statins, non-HDL-C, and apoB concentrations were improved predictors of future major cardiovascular events (Boekholdt et al., 2012). In addition, minor increases in HDL-C in statins-treated patients seems to specifically relate to an increase in HDL2 rather than HDL3. The results of these studies on HDL plasma levels are summarized in Table 2.

\section{Cholesterylester Transfer Protein (CETP) Inhibitors}

Some of the most promising HDL-raising drugs are the CETP inhibitors. CETP is a hydrophobic glycoprotein mainly secreted from the liver and circulating in plasma mainly bound to HDL. CETP reduce circulating HDL-C levels by transferring cholesteryl ester from HDL to larger lipoproteins, such as chylomicrons, very low density lipoprotein (VLDL) and LDL, in exchange for triglyceride. Four CETP inhibitors have reached late-stage clinical development: torcetrapib, dalcetrapib, anacetrapib and evacetrapib, mostly with disappointing results. Indeed meta-analysis concluded that current CETP inhibitors did not reduce cardiovascular mortality (Verdoia et al., 2015). Most recently, the Randomized Evaluation of the Effects of Anacetrapib through Lipid Modification (REVEAL) trial provided promising results (HPS3/TIMI55-Reveal Collaborative Group Bowman et al., 2017). The REVEAL trial found that the primary outcome (first major coronary event) occurred significantly less frequently in patients with atherosclerotic vascular disease treated with anacetrapib after 4.1 years of follow up (HPS3/TIMI55-Reveal Collaborative Group Bowman et al., 2017). This study showed a $104 \%$ increase in HDL-C and a reduction of $17 \mathrm{mg} / \mathrm{dl}$ of non-HDL-C in the anacetrapib group compared to the placebo group. In the conclusion, the authors argued that the reduction in non-HDL-C would be anticipated due to relative reduction in the risk of coronary death or myocardial infarction which was observed. This result reduces the likelihood that other actions of anacetrapib played a major role in modifying the risk of coronary events. In particular, the higher mean level of HDL-C in the anacetrapib group does not appear to have had as large an effect on coronary events (HPS3/TIMI55-Reveal Collaborative Group Bowman et al., 2017). Despite this, the REVEAL trial along with the majority of CETP inhibitor studies did not examine the effects of CETP inhibitors on HDL subclass. Those trials that did so are summarized in Table 2. All indicate that HDL2 is preferentially raised. In addition to this HDL2 increase, evacetrapib monotherapy also increases pre $\beta-1$ HDL but to a lesser extent (Nicholls et al., 2015). In a recent study in mice, anacetrapib and evacetrapib were analyzed for their influence on HDL function, HDL subclass distribution and endothelial function. Expectantly, treatment with both drugs raised HDL-C levels while only evacetrapib increased PON1 activity and RCT (Simic et al., 2017). Similarly to human studies, treatment with both drugs showed increases in large HDL subclasses quantified by nuclear magnetic resonance spectroscopy (Simic et al., 2017). The results of the REVEAL trial are certainly promising, although future studies which examine HDL subclass-specific effects of the treatment will be required to further validate these findings in relation to HDL biochemistry. However, at the time of this review, the manufacturer has made the decision to not pursue its development.

\section{Niacin}

Niacin is the most efficient HDL-C raising drug and mechanisms of action include non-competitive inhibition of hepatocyte microsomal diacylglycerol acyltransferase-2 (DGAT2), an enzyme which catalyzes the final reaction involved in triglyceride synthesis (Ganji et al., 2002) as well as selective inhibition of apoAI uptake without influencing de novo synthesis, which raises HDL-C levels (Jin et al., 1997). Widespread application of niacin treatment has been limited by adverse side-effects

TABLE 2 | Impact of statin and CETP inhibitor therapy on patient lipid profile.

\begin{tabular}{|c|c|c|c|c|c|c|}
\hline Drug & Disease & LDL-C (\%) & HDL-C (\%) & $\begin{array}{l}\text { HDL2/large } \\
\text { HDL (\%) }\end{array}$ & $\begin{array}{l}\text { HDL3/small } \\
\text { HDL (\%) }\end{array}$ & Reference \\
\hline \multirow[t]{6}{*}{ Simvastatin } & None & -40 & Null & +18 & Null & Berthold et al., 2014 \\
\hline & Hypercholesterolemia & -49 & +6 & +28 & -12 & Neuman et al., 1991 \\
\hline & Hypercholesterolemia & -39 & Null & +61 & Null & Gaw et al., 1993 \\
\hline & Hypercholesterolemia & -31 & +7 & +30 & +12 & Johansson et al., 1991 \\
\hline & High risk CVD & -38 & +6 & Null & Null & Franceschini et al., 2007 \\
\hline & Familiar Hyperlipoproteinemia & -33 (LDL1)/-23 (LDL2) & +6 & +10 & Null & Homma et al., 1995 \\
\hline Atorvastatin & $\begin{array}{l}\text { Type } 2 \text { diabetic patients with } \\
\text { ischemic heart disease }\end{array}$ & -47 & +16 & +39 & -10 & Soedamah-Muthu et al., 2003 \\
\hline \multirow[t]{3}{*}{ Pravastatin } & Familiar hyperlipidemia & -32 & +6 & +73 & -8 & Franceschini et al., 1994 \\
\hline & Familiar hyperlipidemia & -36 & Null & \multicolumn{2}{|c|}{ Increase in HDL2:HDL3 ratio } & Guérin et al., 1995 \\
\hline & Hypercholesterolemia & -18 & Null & -10 & +6 & Cheung et al., 1993 \\
\hline Torcetrapib & Familiar hypercholesterolemia & -14 & +54 & +157 & +46 & Kastelein et al., 2007 \\
\hline Anacetrapib & None & -26 & +82 & +373 (HDL2b) & +15 & Krauss et al., 2012 \\
\hline
\end{tabular}

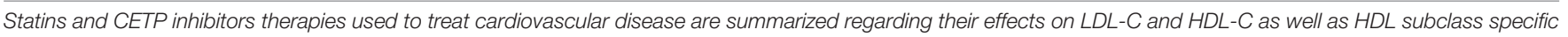
changes. 
TABLE 3 | Impact of niacin and fibrate therapy on patient lipid profile.

\begin{tabular}{|c|c|c|c|c|c|c|}
\hline Drug & Disease & LDL-C (\%) & HDL-C (\%) & $\begin{array}{l}\text { HDL2/large } \\
\text { HDL (\%) }\end{array}$ & $\begin{array}{l}\text { HDL3/small } \\
\text { HDL (\%) }\end{array}$ & Reference \\
\hline $\begin{array}{l}\text { Niacin with statin and } \\
\text { ezetimbe }\end{array}$ & CVD & -13 & +11 & Null & Null & Boden et al., 2011 \\
\hline $\begin{array}{l}\text { Niacin and laropiprant } \\
\text { with simvastatin }\end{array}$ & $\begin{array}{l}\text { Primary } \\
\text { hypercholesterolemia or } \\
\text { mixed hyperlipidemia }\end{array}$ & -45 & +20 & +38 & +14 & Ballantyne et al., 2012 \\
\hline \multirow[t]{3}{*}{ Niacin } & Dyslipidemia & -35 & +15 & +82 & -4 & McKenney et al., 2001 \\
\hline & $\begin{array}{l}\text { Primary } \\
\text { hypercholesterolemia }\end{array}$ & -16 & +23 & +84 & Null & Morgan et al., 2003 \\
\hline & Hyperlipidemia & - & - & +102 & -2 & Toth et al., 2012 \\
\hline Niacin and gemfibrozil & Hyperlipidemia & -20 & +32 & +90 & Null & Superko et al., 2009 \\
\hline Bezafibrate & $\begin{array}{l}\text { Coronary artery disease } \\
\text { and dyslipoproteinemia }\end{array}$ & Null & Null & Null & +7 & Ruotolo et al., 1998 \\
\hline Ciprofibrate & Hyperlipoproteinemia & -17 & +13 & Null & +22 & Guérin et al., 2003 \\
\hline Fenofibrate & No diabetic patients & Null & +22 & -2.3 & +1.9 & Franceschini et al., 2007 \\
\hline
\end{tabular}

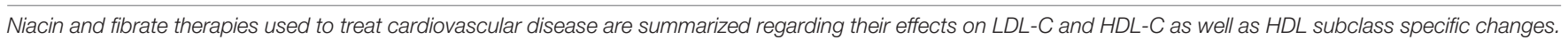

including flushing in patients. It seems that niacin therapy both on its own and in combination with statins preferentially raise HDL2 whilst simultaneously raising HDL-C and lowering triglyceride, LDL and VLDL cholesterol levels (Carlson, 2005), Table 3. It is important to distinguish these outcomes from statin-related effects, as the propensity of niacin to raise HDL2 was shown to be superior to atorvastatin (Toth et al., 2012).

\section{Fibrates}

Fibrates do not reduce LDL-C to the same extent as statins, however, they are still widely prescribed, in many cases as a secondary treatment in combination with statins (Gotto and Opie, 2005; Moutzouri et al., 2010; Katsiki et al., 2013). The mechanism of the multiple actions of fibrate activity can be summarized as: induction of lipoprotein lipolysis; induction of hepatic fatty acid uptake; increased removal of LDL particles; inhibition of cholesterol and triglyceride exchange between HDL and VLDL; stimulation of HDL production via induction of hepatic synthesis of apoAI and apoAII and reduced production of VLDL due to reduction of free fatty acid to the liver (Vu-Dac et al., 1995; Berthou et al., 1996; Staels et al., 1998). Conversely to the aforementioned drugs, fibrate treatment may promote increases in HDL3. Unfortunately, these increases in HDL3 are relatively low and may be insufficient to reduce the risk of cardiovascular event. The effect of fibrate treatment on HDL subclass distribution is summarized in Table 3.

In summary, traditional lipid-lowering drugs have varied influences on HDL subclass distribution. Whilst it is wellunderstood that statins, CETP inhibitors, fibrates and niacin raise HDL-C whilst decreasing $\mathrm{LDL}-\mathrm{C}$, each cause selective increases in HDL2 or HDL3. Statins, CETP inhibitors and niacin raise HDL2 whilst only the fibrates, in a limited number of studies and to a limited extent, have been shown to increase HDL3. These differences may potentially explain why the clinical trials aimed at attenuating low HDL-C levels have been met with such disappointing results. In most cases, the functionally beneficial HDL3 is not raised in combination with total HDL-C.

As reviewed recently by Muthuramu et al. (2017), none of the aforementioned trials have hard clinical outcomes specifically related to HDL-C. This implies that much of the current pharmaceutical-based therapies have causal effects on HDL-C and are not HDL-targeted. This is in agreement with our argument which postulates that current pharmaceutical interventions are not sufficiently specific to HDL, in particular to raising HDL3 and improving HDL function. In this regard, there is a risk of false negative conclusions about the clinical efficiency of surrogate endpoints and biomarkers which do not sufficiently mimic clinically meaningful endpoints (Muthuramu et al., 2017). Of the current available therapies, we propose how reconstituted HDL (rHDL) therapy serves as a potential novel therapy which can target specific HDL subclasses, thereby improving function and reducing risk. Trials examining rHDL therapies are more specific and have better defined clinical endpoints.

\section{HDL RAISING THERAPIES AND HUMORAL AUTOIMMUNITY AGAINST apoAI, AN UNEXPLORED LINK?}

A growing body of evidence indicates that IgG autoantibodies against apoAI (anti-apoAI IgG) exist in a substantial proportion of the general population (up to 20\%) where they represent an independent CVD risk factor (Antiochos et al., 2016) associated with a decreased survival (Antiochos et al., 2017). In different high CVD risk populations associated with or without autoimmune diseases, high levels of anti-apoAI IgG were shown to be independent predictors of major cardiovascular events (Vuilleumier et al., 2010a,b, 2013; Keller et al., 2012; El-Lebedy et al., 2016).

In this context mechanistic studies demonstrated that these antibodies could act as mediators of inflammation, atherogenesis, 


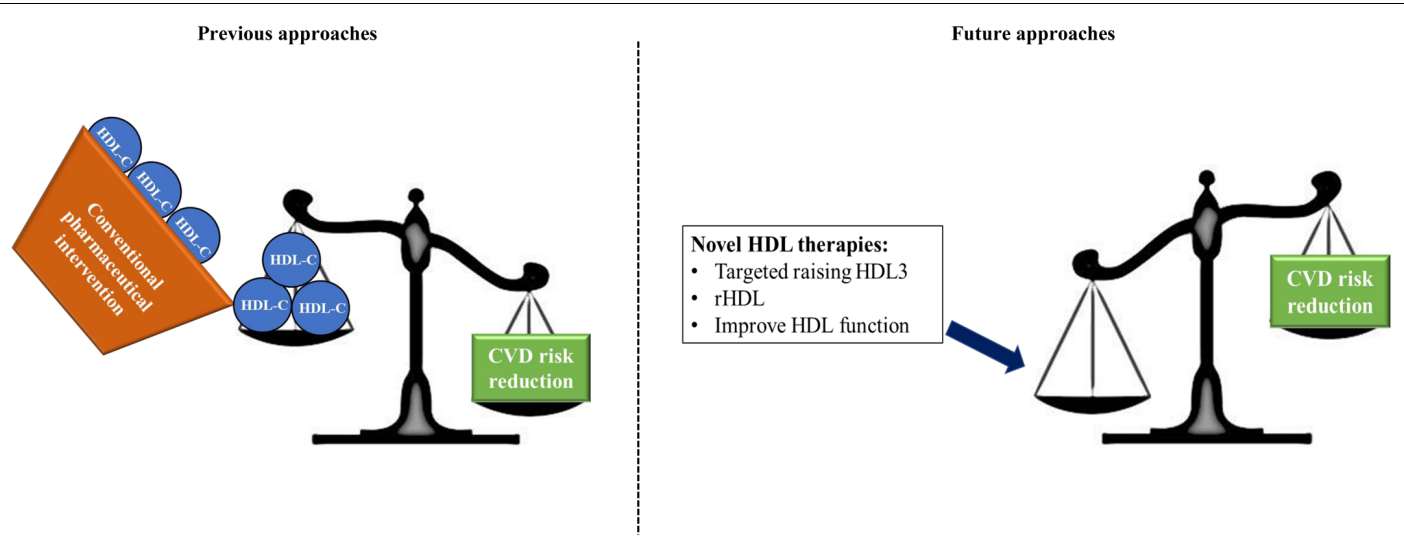

FIGURE 2 | Summary of our current findings. Previous approaches which aimed to improve CVD risk focussed on pharmaceutical increases of HDL-C concentrations. These approaches have largely been met with failure due in part to the inherent complexity of the HDL particle which displays diverse function and heterogeneity. We propose that future approaches should focus on targeted increases in HDL3, which we suggest as the functionally superior HDL subclass; using reconstituted HDL, containing increased concentrations of protective apoAl and S1P; and overall a focus on improvement of HDL function without necessarily raising HDL-C.

heart rate dysregulation, and myocardial necrosis through tolllike receptor-2 and CD14 complex signaling (Montecucco et al., 2011, 2015; Pagano et al., 2012, 2016; Mannic et al., 2015), indicating that these antibodies could represent a new CVD therapeutic target amenable to apoAI mimetic peptide-based immunomodulation (Pagano et al., 2015). However, the reason why these autoantibodies could appear in non-autoimmune conditions remained unclear until the publication of a genomewide association study that highlighted a $\mathrm{Fc}$ receptor like (FCRL) 3 single nucleotide polymorphism as a key genetic determinant underlying the existence of anti-apoAI IgG in the general population (Antiochos et al., 2017). FCRL3 being a major autoimmune susceptibility gene in human, this study provided the first biological rational to explain the existence of these antibodies in humans. Concomitantly, a small-sized phasetwo randomized-controlled trial (EXLPORE) set the proof of principle that HDL-raising therapies (niacin in this case), could induce the production of a sustained and specific anti-apoAI IgG response associated with a loss of the antioxidant function of HDL (Batuca et al., 2017). Given the fact that most, if not all, HDL-raising therapies induce important conformational/size changes of HDL, humoral autoimmune response to apoAI may well-represent a generic effect of most HDL-raising therapies. Interestingly, the EXPLORE trial showed that niacin did not affect anti-HDL antibodies suggesting that the structural changes of the major protective fraction of HDL (apoAI) may drive this autoimmune response, rather than a change in HDL size.

Given the strength of associations reported between anti-apoAI IgG, CVD, and HDL dysfunction, it is tempting to speculate that in genetically prone individuals the humoral autoimmune response induced by HDL-raising therapies could jeopardize the efficacy of such therapeutic modality. Addressing this point in a systematic manner in future HDL-related studies would certainly be welcome given the current paucity of data on this under-explored topic.

\section{NOVEL THERAPY TO TARGET PROTECTIVE HDL SUBCLASS}

Since it can be postulated that particle specific changes are more closely related to cardiovascular risk, novel therapies addressing this are in development which may accomplish improved protection. In this section, we hypothesize an example of such a therapy which may allow for improved cardioprotection owing to a selective increase in cardioprotective HDL subclasses. In this context, In this context, rHDL may be an option. Originally, rHDL composed of apoAI and phospholipids (Jonas, 1985), was exploited for years in experimental laboratory settings to investigate $\mathrm{HDL}$ function. It presents an attractive model to test the roles of individual peptide and lipid components of HDL. Examples of current rHDL therapies include CER-001 (an HDL mimetic agent), CSL112 (an infusible, plasma derived apoAI) and ACP-501 (recombinant human LCAT). These agents have been separately tested and have shown good tolerability with no adverse side effects in patients (Gibson et al., 2016; Shamburek et al., 2016; Keyserling et al., 2017). In patients, administration of rHDL was associated with reduction in plaque size, better endothelial function and increase in anti-inflammatory markers (Nissen et al., 2003; Tardif et al., 2007; Nieuwdorp et al., 2008; Shaw et al., 2008; Patel et al., 2009). rHDL were used in patients with acute coronary syndrome and lead to an increase in plasma HDL-C and a decrease in a decrease in LDL-C (Chenevard et al., 2012). As a caveat to these positive findings, animal studies and HDL-targeted gene therapy studies have indicated that apoAI overexpression did not cause regression of pre-existing atherosclerotic lesions but rather retarded further expansion of pre-existing lesions (Rong et al., 2001; Li et al., 2011; Van Craeyveld et al., 2011). Additionally, a study analyzing CER001 found no difference between placebo and treatment in the reduction of atheroma volume (Tardif et al., 2014). The effects of CER-001, may however, be dose-dependent (Keyserling et al., 2017). Importantly, addition of rHDL improved HDL RCT in 
a number of studies (Gibson et al., 2016; Zheng et al., 2016; Keyserling et al., 2017). The composition of rHDL resembles the pre $\beta$ - 1 HDL particle and is highly modifiable. rHDL can absorb many products including cholesterol, proteins, and S1P in vivo. These observations strongly suggest that rHDL can therefore be protective through improving RCT or by absorbing beneficial proteins.

It would be interesting to assess the ability to improve these beneficial capacities by modulating rHDL composition. In this context our group has investigated the beneficial effect of the addition of S1P to basal rHDL. We demonstrated experimentally that adding S1P improves the cardiac survival capacity in vitro, ex vivo, and in vivo (Frias et al., 2010; Brulhart-Meynet et al., 2015). The HDL3 subclass, contains $2-3$ times more S1P than HDL2 (Kontush et al., 2007; Lee et al., 2010). It seems that the S1P content influences HDL-induced cardioprotection and that S1P-enriched rHDL offer a better protection (BrulhartMeynet et al., 2015). But until now, human studies using rHDL have not considered the S1P content in their preparations but rather focused on the apoAI content. In addition, the peptide components of HDL outlined in this review (such as PON1, apoJ, or apoM) could be added to better improve cardioprotective capacities. In this regard, engineering a functionally superior rHDL may be possible for patient treatment. This intervention has been shown to improve cardioprotection in patients (see review, Darabi et al., 2016). Some studies have also indicated that infusion with rHDL can influence apoAI concentrations and lipidome profiles of native HDL (Nanjee et al., 1999); increase the concentrations of pre $\beta-1$ HDL (Nanjee et al., 2001) and improve anti-inflammatory function of native HDL (Patel et al., 2009). More detailed information on the apoAI-directed therapies can be found in the review (Millar and Cuchel, 2015).

\section{REFERENCES}

Alaupovic, P. (2003). The concept of apolipoprotein-defined lipoprotein families and its clinical significance. Curr. Atheroscler. Rep. 5, 459-467. doi: 10.1007/ s11883-003-0036-8

Albers, J. J., Slee, A., Fleg, J. L., O’Brien, K. D., and Marcovina, S. M. (2016). Relationship of baseline HDL subclasses, small dense LDL and LDL triglyceride to cardiovascular events in the AIM-HIGH clinical trial. Atherosclerosis 251, 454-459. doi: 10.1016/j.atherosclerosis.2016.06.019

Ansell, B. J., Navab, M., Hama, S., Kamranpour, N., Fonarow, G., Hough, G., et al. (2003). Inflammatory/antiinflammatory properties of high-density lipoprotein distinguish patients from control subjects better than highdensity lipoprotein cholesterol levels and are favorably affected by simvastatin treatment. Circulation 108, 2751-2756. doi: 10.1161/01.CIR.0000103624. 14436.4B

Antiochos, P., Marques-Vidal, P., Virzi, J., Pagano, S., Satta, N., Bastardot, F., et al. (2016). Association between anti-apolipoprotein A-1 antibodies and cardiovascular disease in the general population. Thromb. Haemost. 116, 764-771. doi: 10.1160/TH16-03-0248

Antiochos, P., Marques-Vidal, P., Virzi, J., Pagano, S., Satta, N., Hartley, O., et al. (2017). Anti-apolipoprotein a-1 IgG predict all-cause mortality and are associated with Fc receptor-like 3 polymorphisms. Front. Immunol. 8:437. doi: 10.3389/fimmu.2017.00437

Ashby, D. T., Rye, K.-A., Clay, M. A., Vadas, M. A., Gamble, J. R., and Barter, P. J. (1998). Factors influencing the ability of HDL to inhibit expression of vascular cell adhesion molecule-1 in endothelial cells. Arterioscler. Thromb. Vasc. Biol. 18, 1450-1455. doi: 10.1161/01.ATV.18.9.1450

\section{CONCLUSION}

We have discussed in this review that HDL is an extremely complex particle composed of an array of lipids and peptides which result in functionally and structurally distinct $\mathrm{HDL}$ subclasses. We have suggested, similar to Kontush and Chapman (2006), that the smaller HDL subclass, HDL3 performs a functionally superior role to the larger HDL2 owing in particular to increased association with cardioprotective enzymes and lipids such as S1P. Drug therapies which raise HDL-C have been met with disappointing results. We recommend that future research focuses to a greater extent on HDL functionality and subclass distribution. Novel therapies such as rHDL infusion may then permit selectively raising the levels of functionally superior HDL subclasses thereby reducing cardiovascular risk in patients (Figure 2).

\section{AUTHOR CONTRIBUTIONS}

NW assimilated and compiled the final manuscript which was written in part by SP, SL, RS, NV, RJ, and MF. All authors contributed equally in review of the final manuscript.

\section{ACKNOWLEDGMENTS}

This work was supported by the Fondation Gustave et Simone Prévot, Fondation Carlos et Elsie de Reuter, Fondation Ernst et Lucie Schmidheiny, Fondation pour la Lutte contre le Cancer et pour des Recherches Médico-Biologiques and Jubiläumsstiftung SwissLife (MAF).

Assmann, G., Schulte, H., Von Eckardstein, A., and Huang, Y. (1996). High-density lipoprotein cholesterol as a predictor of coronary heart disease risk. The PROCAM experience and pathophysiological implications for reverse cholesterol transport. Atherosclerosis 124(Suppl.), S11-S20.

Asztalos, B. F., Tani, M., and Schaefer, E. J. (2011). Metabolic and functional relevance of HDL subspecies. Curr. Opin. Lipidol. 22, 176-185. doi: 10.1097/ MOL.0b013e3283468061

Ayub, A., Mackness, M. I., Arrol, S., Mackness, B., Patel, J., and Durrington, P. N. (1999). Serum paraoxonase after myocardial infarction. Arterioscler. Thromb. Vasc. Biol. 19, 330-335. doi: 10.1161/01.ATV.19.2.330

Badimon, J. J., Badimon, L., and Fuster, V. (1990). Regression of atherosclerotic lesions by high density lipoprotein plasma fraction in the cholesterol-fed rabbit. J. Clin. Invest. 85, 1234-1241. doi: 10.1172/JCI114558

Badimon, J. J., Badimon, L., Galvez, A., Dische, R., and Fuster, V. (1989). High density lipoprotein plasma fractions inhibit aortic fatty streaks in cholesterolfed rabbits. Lab. Invest. 60, 455-461.

Badimon, L., Padró, T., and Cubedo, J. (2017). Protein changes in non-LDLlipoproteins in familial hypercholesterolemia: implications in cardiovascular disease manifestation and outcome. Curr. Opin. Lipidol. 28, 427-433. doi: 10.1097/MOL.0000000000000441

Ballantyne, C., Gleim, G., Liu, N., Sisk, C. M., Johnson-Levonas, A. O., and Mitchel, Y. (2012). Effects of coadministered extended-release niacin/laropiprant and simvastatin on lipoprotein subclasses in patients with dyslipidemia. J. Clin. Lipidol. 6, 235-243. doi: 10.1016/j.jacl.2011.11.004

Barter, P. J., Nicholls, S., Rye, K.-A., Anantharamaiah, G., Navab, M., and Fogelman, A. M. (2004). Antiinflammatory properties of HDL. Circ. Res. 95, 764-772. doi: 10.1161/01.RES.0000146094.59640.13 
Barter, P. J., and Rye, K. A. (1996). High density lipoproteins and coronary heart disease. Atherosclerosis 121, 1-12. doi: 10.1016/0021-9150(95)05675-0

Batuca, J. R., Amaral, M. C., Favas, C., Paula, F. S., Ames, P. R., Papoila, A. L., et al. (2017). Extended-release niacin increases anti-apolipoprotein A-I antibodies that block the antioxidant effect of high-density lipoprotein-cholesterol: the EXPLORE clinical trial. Br. J. Clin. Pharmacol. 83, 1002-1010. doi: 10.1111/bcp. 13198

Berthold, H. K., Rizzo, M., Spenrath, N., Montalto, G., Krone, W., and GouniBerthold, I. (2014). Effects of lipid-lowering drugs on high-density lipoprotein subclasses in healthy men-a randomized trial. PLOS ONE 9:e91565. doi: 10.1371/journal.pone. 0091565

Berthou, L., Duverger, N., Emmanuel, F., Langouët, S., Auwerx, J., Guillouzo, A., et al. (1996). Opposite regulation of human versus mouse apolipoprotein AI by fibrates in human apolipoprotein AI transgenic mice. J. Clin. Invest. 97, 2408-2416. doi: 10.1172/JCI118687

Besler, C., Heinrich, K., Rohrer, L., Doerries, C., Riwanto, M., Shih, D. M., et al. (2011). Mechanisms underlying adverse effects of HDL on eNOSactivating pathways in patients with coronary artery disease. J. Clin. Invest. 121, 2693-2708. doi: 10.1172/JCI42946

Blache, D., Gautier, T., Tietge, U. J., and Lagrost, L. (2012). Activated platelets contribute to oxidized low-density lipoproteins and dysfunctional high-density lipoproteins through a phospholipase A2-dependent mechanism. FASEB J. 26, 927-937. doi: 10.1096/fj.11-191593

Boden, W. E., Probstfield, J. L., Anderson, T., Chaitman, B. R., DesvignesNickens, P., Koprowicz, K. M., et al. (2011). Niacin in patients with low $\mathrm{Hdl}$ cholesterol levels receiving intensive statin therapy. N. Engl. J. Med. 365, 2255-2267. doi: 10.1056/NEJMoa1107579

Boekholdt, S. M., Arsenault, B. J., Mora, S., Pedersen, T. R., Larosa, J. C., Nestel, P. J., et al. (2012). Association of LDL cholesterol, non-HDL cholesterol, and apolipoprotein B levels with risk of cardiovascular events among patients treated with statins: a meta-analysis. JAMA 307, 1302-1309. doi: 10.1001/jama. 2012.366

Brinck, J. W., Thomas, A., Lauer, E., Jornayvaz, F. R., Brulhart-Meynet, M.-C., Prost, J.-C., et al. (2016). Diabetes mellitus is associated with reduced highdensity lipoprotein sphingosine-1-phosphate content and impaired highdensity lipoprotein cardiac cell protection. Arterioscler. Thromb. Vasc. Biol. 36, 817-824. doi: 10.1161/ATVBAHA.115.307049

Brites, F. D., Bonavita, C. D., De Geitere, C., Cloës, M., Delfly, B., Yael, M. J., et al. (2000). Alterations in the main steps of reverse cholesterol transport in male patients with primary hypertriglyceridemia and low HDL-cholesterol levels. Atherosclerosis 152, 181-192. doi: 10.1016/S0021-9150(99)00452-9

Brownell, N., and Rohatgi, A. (2016). Modulating cholesterol efflux capacity to improve cardiovascular disease. Curr. Opin. Lipidol. 27, 398-407. doi: 10.1097/ MOL.0000000000000317

Brugger, P., Kullich, W., Klein, G., and Kostner, G. (1986). Plasma concentrations of high-density lipoprotein (hdl)-2 and hdl-3 in myocardial infarction survivors and in control subjects. Clin. Cardiol. 9, 273-276. doi: 10.1002/clc.496009 0608

Brulhart-Meynet, M.-C., Braunersreuther, V., Brinck, J., Montecucco, F., Prost, J.-C., Thomas, A., et al. (2015). Improving reconstituted Hdl composition for efficient post-ischemic reduction of ischemia reperfusion injury. PLOS ONE 10:e0119664. doi: 10.1371/journal.pone.0119664

Cabana, V., Lukens, J., Rice, K. S., Hawkins, T. J., and Getz, G. (1996). HDL content and composition in acute phase response in three species: triglyceride enrichment of HDL a factor in its decrease. J. Lipid Res. 37, 2662-2674.

Calabresi, L., Gomaraschi, M., Villa, B., Omoboni, L., Dmitrieff, C., and Franceschini, G. (2002). Elevated soluble cellular adhesion molecules in subjects with low HDL-cholesterol. Arterioscler. Thromb. Vasc. Biol. 22, 656-661. doi: $10.1161 / \mathrm{hq} 0402.105901$

Camont, L., Lhomme, M., Rached, F., Le Goff, W., Nègre-Salvayre, A., Salvayre, R., et al. (2013). Small, dense high-density lipoprotein-3 particles are enriched in negatively charged phospholipids relevance to cellular cholesterol efflux, antioxidative, antithrombotic, anti-inflammatory, and antiapoptotic functionalities. Arterioscler. Thromb. Vasc. Biol. 33, 2715-2723. doi: 10.1161/ ATVBAHA.113.301468

Carlson, L. A. (2005). Nicotinic acid: the broad-spectrum lipid drug. A 50th anniversary review. J. Intern. Med. 258, 94-114. doi: 10.1111/j.1365-2796.2005. 01528.x
Chapman, M. J. (1986). Comparative analysis of mammalian plasma lipoproteins. Methods Enzymol. 128, 70-143. doi: 10.1016/0076-6879(86)28063-5

Chenevard, R., Hürlimann, D., Spieker, L., Bechir, M., Enseleit, F., Hermann, M., et al. (2012). Reconstituted HDL in acute coronary syndromes. Cardiovasc. Ther. 30, e51-e57. doi: 10.1111/j.1755-5922.2010.00221.x

Cheung, M. C., Austin, M. A., Moulin, P., Wolf, A. C., Cryer, D., and Knopp, R. H. (1993). Effects of pravastatin on apolipoprotein-specific high density lipoprotein subpopulations and low density lipoprotein subclass phenotypes in patients with primary hypercholesterolemia. Atherosclerosis 102, 107-119. doi: 10.1016/0021-9150(93)90089-D

Cockerill, G. W., Rye, K.-A., Gamble, J. R., Vadas, M. A., and Barter, P. J. (1995). High-density lipoproteins inhibit cytokine-induced expression of endothelial cell adhesion molecules. Arterioscler. Thromb. Vasc. Biol. 15, 1987-1994. doi: 10.1161/01.ATV.15.11.1987

Cockerill, G. W., Saklatvala, J., Ridley, S. H., Yarwood, H., Miller, N. E., Oral, B., et al. (1999). High-density lipoproteins differentially modulate cytokineinduced expression of E-selectin and cyclooxygenase-2. Arterioscler. Thromb. Vasc. Biol. 19, 910-917. doi: 10.1161/01.ATV.19.4.910

Cubedo, J., Padró, T., Alonso, R., Cinca, J., Mata, P., and Badimon, L. (2012). Differential proteomic distribution of Ttr (pre-albumin) forms in serum and HDL of patients with high cardiovascular risk. Atherosclerosis 222, 263-269. doi: 10.1016/j.atherosclerosis.2012.02.024

Cubedo, J., Padró, T., Alonso, R., Mata, P., and Badimon, L. (2016). ApoL1 levels in high density lipoprotein and cardiovascular event presentation in patients with familial hypercholesterolemia. J. Lipid Res. 57, 1059-1073. doi: 10.1194/jlr. P061598

Cubedo, J., Padró, T., García-Arguinzonis, M., Vilahur, G., Miñambres, I., Pou, J. M., et al. (2015). A novel truncated form of apolipoprotein AI transported by dense LDL is increased in diabetic patients. J. Lipid Res. 56, 1762-1773. doi: $10.1194 /$ jlr.P057513

Curtiss, L. K., Bonnet, D. J., and Rye, K.-A. (2000). The conformation of apolipoprotein AI in high-density lipoproteins is influenced by core lipid composition and particle size: a surface plasmon resonance study. Biochemistry 39, 5712-5721. doi: 10.1021/bi992902m

Damirin, A., Tomura, H., Komachi, M., Tobo, M., Sato, K., Mogi, C., et al. (2005). Sphingosine 1-phosphate receptors mediate the lipid-induced cAMP accumulation through cyclooxygenase-2/prostaglandin I2 pathway in human coronary artery smooth muscle cells. Mol. Pharmacol. 67, 1177-1185. doi: 10. 1124/mol.104.004317

Darabi, M., Guillas-Baudouin, I., Le Goff, W., Chapman, M. J., and Kontush, A. (2016). Therapeutic applications of reconstituted HDL: when structure meets function. Pharmacol. Ther. 157, 28-42. doi: 10.1016/j.pharmthera.2015. 10.010

Davidson, W. S., Silva, R. G. D., Chantepie, S., Lagor, W. R., Chapman, M. J., and Kontush, A. (2009). Proteomic analysis of defined HDL subpopulations reveals particle-specific protein clusters relevance to antioxidative function. Arterioscler. Thromb. Vasc. Biol. 29, 870-876. doi: 10.1161/ATVBAHA.109. 186031

de la Llera-Moya, M., Drazul-Schrader, D., Asztalos, B. F., Cuchel, M., Rader, D. J., and Rothblat, G. H. (2010). The ability to promote efflux via $\mathrm{ABCA} 1$ determines the capacity of serum specimens with similar high-density lipoprotein cholesterol to remove cholesterol from macrophages. Arterioscler. Thromb. Vasc. Biol. 30, 796-801. doi: 10.1161/ATVBAHA.109.199158

Ditah, C., Otvos, J., Nassar, H., Shaham, D., Sinnreich, R., and Kark, J. D. (2016). Small and medium sized HDL particles are protectively associated with coronary calcification in a cross-sectional population-based sample. Atherosclerosis 251, 124-131. doi: 10.1016/j.atherosclerosis.2016.06.010

Durrington, P., Mackness, B., and Mackness, M. (2001). Paraoxonase and atherosclerosis. Arterioscler. Thromb. Vasc. Biol. 21, 473-480. doi: 10.1161/01. ATV.21.4.473

El-Lebedy, D., Rasheed, E., Kafoury, M., Abd-El Haleem, D., Awadallah, E., and Ashmawy, I. (2016). Anti-apolipoprotein A-1 autoantibodies as risk biomarker for cardiovascular diseases in type 2 diabetes mellitus. J. Diabetes Complications 30, 580-585. doi: 10.1016/j.jdiacomp.2016.02.014

Escudero, I., Martínez-González, J., Alonso, R., Mata, P., and Badimon, L. (2003). Experimental and interventional dietary study in humans on the role of HDL fatty acid composition in PGI2 release and Cox-2 expression by VSMC. Eur. J. Clin. Invest. 33, 779-786. doi: 10.1046/j.1365-2362.2003.01221.x 
Estruch, M., Miñambres, I., Sanchez-Quesada, J. L., Soler, M., Pérez, A., OrdoñezLlanos, J., et al. (2017). Increased inflammatory effect of electronegative LDL and decreased protection by HDL in type 2 diabetic patients. Atherosclerosis 265, 292-298. doi: 10.1016/j.atherosclerosis.2017.07.015

Fleisher, L. N., Tall, A., Witte, L., Miller, R., and Cannon, P. (1982). Stimulation of arterial endothelial cell prostacyclin synthesis by high density lipoproteins. J. Biol. Chem. 257, 6653-6655.

Franceschini, G., Calabresi, L., Colombo, C., Favari, E., Bernini, F., and Sirtori, C. R. (2007). Effects of fenofibrate and simvastatin on Hdl-related biomarkers in lowHdl patients. Atherosclerosis 195, 385-391. doi: 10.1016/j.atherosclerosis.2006. 10.017

Franceschini, G., Cassinotti, M., Vecchio, G., Gianfranceschi, G., Pazzucconi, F., Murakami, T., et al. (1994). Pravastatin effectively lowers LDL cholesterol in familial combined hyperlipidemia without changing LDL subclass pattern. Arterioscler. Thromb. Vasc. Biol. 14, 1569-1575. doi: 10.1161/01.ATV.14.10. 1569

Frias, M. A., Lang, U., Gerber-Wicht, C., and James, R. W. (2010). Native and reconstituted HDL protect cardiomyocytes from doxorubicin-induced apoptosis. Cardiovasc. Res. 85, 118-126. doi: 10.1093/cvr/cvp289

Frias, M. A., Lecour, S., James, R. W., and Pedretti, S. (2012). High density lipoprotein/sphingosine-1-phosphate-induced cardioprotection: role of STAT3 as part of the SAFE pathway. JAKSTAT 1, 92-100. doi: 10.4161/jkst.19754

Ganji, S., Tavintharan, S., Zhu, D., Kamanna, V., and Kashyap, M. (2002). Niacin non-competitively inhibits hepatocyte diacylglycerol acyltransferase, a key enzyme for triglyceride synthesis. Arterioscler. Thromb. Vasc. Biol. 22:878.

Gaw, A., Packard, C. J., Murray, E. F., Lindsay, G. M., Griffin, B. A., Caslake, M. J., et al. (1993). Effects of simvastatin on apoB metabolism and LDL subfraction distribution. Arterioscler. Thromb. Vasc. Biol. 13, 170-189. doi: 10.1161/01. ATV.13.2.170

GBD 2013 Mortality and Causes of Death Collaborators (2015). Global, regional, and national age-sex specific all-cause and cause-specific mortality for 240 causes of death, 1990-2013: a systematic analysis for the Global Burden of Disease Study 2013. Lancet 385, 117-171. doi: 10.1016/S0140-6736(14) 61682-2

Gibson, C. M., Korjian, S., Tricoci, P., Daaboul, Y., Yee, M., Jain, P., et al. (2016). Safety and tolerability of CSL112, a reconstituted, infusible, plasmaderived apolipoprotein AI, after acute myocardial infarction: the AEGIS-I trial (ApoA-I event reducing in ischemic syndromes I). Circulation 134, 1918-1930. doi: 10.1161/CIRCULATIONAHA.116.025687

Gillard, B. K., Lin, H. Y., Massey, J. B., and Pownall, H. J. (2009). Apolipoproteins A-I, A-II and E are independently distributed among intracellular and newly secreted HDL of human hepatoma cells. Biochim. Biophys. Acta 1791, 1125-1132. doi: 10.1016/j.bbalip.2009.07.004

Glomset, J. A. (1968). The plasma lecithin: cholesterol acyltransferase reaction. J. Lipid Res. 9, 155-167.

Goldbourt, U., Yaari, S., and Medalie, J. H. (1997). Isolated low HDL cholesterol as a risk factor for coronary heart disease mortality. A 21-year follow-up of 8000 men. Arterioscler. Thromb. Vasc. Biol. 17, 107-113. doi: 10.1161/01.ATV.17. 1.107

Gomaraschi, M., Calabresi, L., Rossoni, G., Iametti, S., Franceschini, G., Stonik, J. A., et al. (2008). Anti-inflammatory and cardioprotective activities of synthetic high-density lipoprotein containing apolipoprotein AI mimetic peptides. J. Pharmacol. Exp. Ther. 324, 776-783. doi: 10.1124/jpet.107. 129411

Gordon, T., Castelli, W. P., Hjortland, M. C., Kannel, W. B., and Dawber, T. R. (1977). High density lipoprotein as a protective factor against coronary heart disease. The Framingham study. Am. J. Med. 62, 707-714. doi: 10.1016/00029343(77)90874-9

Gotto, A. M., and Opie, L. H. (2005). "Lipid-lowering and antiatherosclerotic drugs," in Drugs for the Heart, 6th Edn, eds B. O. Gersh and L. H. Opie (Minneapolis, MN: Elsevier).

Guérin, M., Dolphin, P. J., Talussot, C., Gardette, J., Berthézène, F., and Chapman, M. J. (1995). Pravastatin modulates cholesteryl ester transfer from HDL to apoB-containing lipoproteins and lipoprotein subspecies profile in familial hypercholesterolemia. Arterioscler. Thromb. Vasc. Biol. 15, 1359-1368. doi: 10.1161/01.ATV.15.9.1359

Guérin, M., Le Goff, W., Frisdal, E., Schneider, S., Milosavljevic, D., Bruckert, E., et al. (2003). Action of ciprofibrate in type IIB hyperlipoproteinemia: modulation of the atherogenic lipoprotein phenotype and stimulation of highdensity lipoprotein-mediated cellular cholesterol efflux. J. Clin. Endocrinol. Metab. 88, 3738-3746. doi: 10.1210/jc.2003-030191

Hafiane, A., and Genest, J. (2017). ATP binding cassette A1 (ABCA1) mediates microparticle formation during high-density lipoprotein (HDL) biogenesis. Atherosclerosis 257, 90-99. doi: 10.1016/j.atherosclerosis.2017.01.013

Han, C. Y., Tang, C., Guevara, M. E., Wei, H., Wietecha, T., Shao, B., et al. (2016). Serum amyloid A impairs the antiinflammatory properties of Hdl. J. Clin. Invest. 126, 266-281. doi: 10.1172/JCI83475

Hessler, J. R., Robertson, A. L., and Chisolm, G. M. (1979). LDL-induced cytotoxicity and its inhibition by HDL in human vascular smooth muscle and endothelial cells in culture. Atherosclerosis 32, 213-229. doi: 10.1016/00219150(79)90166-7

Holy, E. W., Besler, C., Reiner, M. F., Camici, G. G., Manz, J., Beer, J. H., et al. (2014). High-density lipoprotein from patients with coronary heart disease loses anti-thrombotic effects on endothelial cells: impact on arterial thrombus formation. Thromb. Haemost. 112, 1024-1035. doi: 10.1160/TH13-09-0775

Homma, Y., Ozawa, H., Kobayashi, T., Yamaguchi, H., Sakane, H., and Nakamura, H. (1995). Effects of simvastatin on plasma lipoprotein subfractions, cholesterol esterification rate, and cholesteryl ester transfer protein in type II hyperlipoproteinemia. Atherosclerosis 114, 223-234. doi: 10.1016/00219150(94)05487-4

HPS3/TIMI55-Reveal Collaborative Group Bowman, L., Hopewell, J. C., Chen, F., Wallendszus, K., Stevens, W., et al. (2017). Effects of anacetrapib in patients with atherosclerotic vascular disease. N. Engl. J. Med. 377, 1217-1227. doi: 10.1056/NEJMoa1706444

Igarashi, J., Miyoshi, M., Hashimoto, T., Kubota, Y., and Kosaka, H. (2007). Statins induce S1P1 receptors and enhance endothelial nitric oxide production in response to high-density lipoproteins. Br. J. Pharmacol. 150, 470-479. doi: 10.1038/sj.bjp.0707114

Ishikawa, T., Ayaori, M., Uto-Kondo, H., Nakajima, T., Mutoh, M., and Ikewaki, K. (2015). High-density lipoprotein cholesterol efflux capacity as a relevant predictor of atherosclerotic coronary disease. Atherosclerosis 242, 318-322. doi: 10.1016/j.atherosclerosis.2015.06.028

Istvan, E. S., and Deisenhofer, J. (2001). Structural mechanism for statin inhibition of HMG-CoA reductase. Science 292, 1160-1164. doi: 10.1126/science.1059344

Jafri, H., Alsheikh-Ali, A. A., and Karas, R. H. (2010). Meta-analysis: statin therapy does not alter the association between low levels of high-density lipoprotein cholesterol and increased cardiovascular risk. Ann. Intern. Med. 153, 800-808. doi: 10.7326/0003-4819-153-12-201012210-00006

Jeppesen, J., Hein, H. O., Suadicani, P., and Gyntelberg, F. (2000). High triglycerides and low HDL cholesterol and blood pressure and risk of ischemic heart disease. Hypertension 36, 226-232. doi: 10.1161/01.HYP.36.2.226

Jin, F.-Y., Kamanna, V. S., and Kashyap, M. L. (1997). Niacin decreases removal of high-density lipoprotein apolipoprotein AI but not cholesterol ester by Hep G2 cells implication for reverse cholesterol transport. Arterioscler. Thromb. Vasc. Biol. 17, 2020-2028. doi: 10.1161/01.ATV.17.10.2020

Jing, X.-D., Wei, X.-M., Deng, S.-B., Du, J.-L., Liu, Y.-J., and She, Q. (2015). The relationship between the high-density lipoprotein (HDL)-associated sphingosine-1-phosphate (S1P) and coronary in-stent restenosis. Clin. Chim. Acta 446, 248-252. doi: 10.1016/j.cca.2015.04.038

Johansson, J., Carlson, L. A., Landou, C., and Hamsten, A. (1991). High density lipoproteins and coronary atherosclerosis. A strong inverse relation with the largest particles is confined to normotriglyceridemic patients. Arterioscler. Thromb. Vasc. Biol. 11, 174-182. doi: 10.1161/01.ATV.11.1.174

Jonas, A. (1985). Reconstitution of high-density lipoproteins. Methods Enzymol. 128, 553-582. doi: 10.1016/0076-6879(86)28092-1

Kastelein, J. J., Van Leuven, S. I., Burgess, L., Evans, G. W., Kuivenhoven, J. A., Barter, P. J., et al. (2007). Effect of torcetrapib on carotid atherosclerosis in familial hypercholesterolemia. N. Engl. J. Med. 356, 1620-1630. doi: 10.1056/ NEJMoa071359

Katsiki, N., Nikolic, D., Montalto, G., Banach, M., Mikhailidis, D. P., and Rizzo, M. (2013). The role of fibrate treatment in dyslipidemia: an overview. Curr. Pharm. Des. 19, 3124-3131. doi: 10.2174/1381612811319170020

Kavo, A. E., Rallidis, L. S., Sakellaropoulos, G. C., Lehr, S., Hartwig, S., Eckel, J., et al. (2012). Qualitative characteristics of $\mathrm{Hdl}$ in young patients of an acute myocardial infarction. Atherosclerosis 220, 257-264. doi: 10.1016/j. atherosclerosis.2011.10.017 
Keller, P. F., Pagano, S., Roux-Lombard, P., Sigaud, P., Rutschmann, O., Mach, F., et al. (2012). Autoantibodies against apolipoprotein A-1 and phosphorylcholine for diagnosis of non-ST-segment elevation myocardial infarction. J. Intern. Med. 271, 451-462. doi: 10.1111/j.1365-2796.2011.02479.x

Keyserling, C. H., Barbaras, R., Benghozi, R., and Dasseux, J.-L. (2017). Development of CER-001: preclinical dose selection through to phase i clinical findings. Clin. Drug Investig. 37, 483-491. doi: 10.1007/s40261-017-0506-3

Khera, A. V., Cuchel, M., De La Llera-Moya, M., Rodrigues, A., Burke, M. F., Jafri, K., et al. (2011). Cholesterol efflux capacity, high-density lipoprotein function, and atherosclerosis. N. Engl. J. Med. 364, 127-135. doi: 10.1056/ NEJMoa1001689

Kimura, T., Sato, K., Kuwabara, A., Tomura, H., Ishiwara, M., Kobayashi, I., et al. (2001). Sphingosine 1-phosphate may be a major component of plasma lipoproteins responsible for the cytoprotective actions in human umbilical vein endothelial cells. J. Biol. Chem. 276, 31780-31785. doi: 10.1074/jbc.M104353200

Kontush, A., Chantepie, S., and Chapman, M. J. (2003). Small, dense HDL particles exert potent protection of atherogenic LDL against oxidative stress. Arterioscler. Thromb. Vasc. Biol. 23, 1881-1888. doi: 10.1161/01.ATV.0000091338.93223.E8

Kontush, A., and Chapman, M. J. (2006). Antiatherogenic small, dense HDLguardian angel of the arterial wall? Nat. Clin. Pract. Cardiovasc. Med. 3, 144-153. doi: 10.1038/ncpcardio0500

Kontush, A., Lhomme, M., and Chapman, M. J. (2013). Unraveling the complexities of the HDL lipidome. J. Lipid Res. 54, 2950-2963. doi: 10.1194/ jlr.R036095

Kontush, A., Therond, P., Zerrad, A., Couturier, M., Négre-Salvayre, A., De Souza, J. A., et al. (2007). Preferential sphingosine-1-phosphate enrichment and sphingomyelin depletion are key features of small dense HDL3 particles relevance to antiapoptotic and antioxidative activities. Arterioscler. Thromb. Vasc. Biol. 27, 1843-1849. doi: 10.1161/ATVBAHA.107.145672

Krauss, R. M., Wojnooski, K., Orr, J., Geaney, J. C., Pinto, C. A., Liu, Y., et al. (2012). Changes in lipoprotein subfraction concentration and composition in healthy individuals treated with the CETP inhibitor anacetrapib. J. Lipid Res. 53, 540-547. doi: 10.1194/jlr.M018010

Kühnast, S., Fiocco, M., Van Der Hoorn, J. W., Princen, H. M., and Jukema, J. W. (2015). Innovative pharmaceutical interventions in cardiovascular disease: focusing on the contribution of non-HDL-C/LDL-C-lowering versus HDL-CraisingA systematic review and meta-analysis of relevant preclinical studies and clinical trials. Eur. J. Pharmacol. 763, 48-63. doi: 10.1016/j.ejphar.2015. 03.089

Kunutsor, S. K., Kieneker, L. M., Bakker, S. J., James, R. W., and Dullaart, R. P. (2017). The inverse association of Hdl-cholesterol with future risk of hypertension is not modified by its antioxidant constituent, paraoxonase1: the PREVEND prospective cohort study. Atherosclerosis 263, 219-226. doi: 10.1016/j.atherosclerosis.2017.06.353

Lee, M.-H., Hammad, S. M., Semler, A. J., Luttrell, L. M., Lopes-Virella, M. F., and Klein, R. L. (2010). HDL3, but not HDL2, stimulates plasminogen activator inhibitor-1 release from adipocytes: the role of sphingosine-1-phosphate. J. Lipid Res. 51, 2619-2628. doi: 10.1194/jlr.M003988

Lewis, K. E., Kirk, E. A., Mcdonald, T. O., Wang, S., Wight, T. N., O’brien, K. D., et al. (2004). Increase in serum amyloid a evoked by dietary cholesterol is associated with increased atherosclerosis in mice. Circulation 110, 540-545. doi: 10.1161/01.CIR.0000136819.93989.E1

Li, R., Chao, H., Ko, K. W., Cormier, S., Dieker, C., Nour, E. A., et al. (2011). Gene therapy targeting LDL cholesterol but not HDL cholesterol induces regression of advanced atherosclerosis in a mouse model of familial hypercholesterolemia. J. Genet. Syndr. Gene Ther. 2:106. doi: 10.4158/EP161445.RA

Lindgren, F. T., Jensen, L. C., and Hatch, F. T. (1972). "The isolation and quantitative analysis of serum lipoproteins," in Blood Lipids and Lipoproteins; Quantitation, Composition, and Metabolism, ed. G. J. Nelson (New York, NY: Wiley-Interscience).

Liu, D., Ji, L., Wang, Y., and Zheng, L. (2012). Cyclooxygenase-2 expression, prostacyclin production and endothelial protection of high-density lipoprotein. Cardiovasc. Haematol. Disord. Drug Targets 12, 98-105. doi: 10.2174/ 1871529X11202020098

Lüscher, T. F., Landmesser, U., Von Eckardstein, A., and Fogelman, A. M. (2014). High-density lipoprotein: vascular protective effects, dysfunction, and potential as therapeutic target. Circ. Res. 114, 171-182. doi: 10.1161/CIRCRESAHA.114. 300935
Mackness, B., Durrington, P., Mcelduff, P., Yarnell, J., Azam, N., Watt, M., et al. (2003). Low paraoxonase activity predicts coronary events in the Caerphilly prospective study. Circulation 107, 2775-2779. doi: 10.1161/01.CIR. 0000070954.00271 .13

Mackness, M. I., Arrol, S., Abbott, C., and Durrington, P. N. (1993). Protection of low-density lipoprotein against oxidative modification by high-density lipoprotein associated paraoxonase. Atherosclerosis 104, 129-135. doi: 10.1016/ 0021-9150(93)90183-U

Mackness, M. I., Arrol, S., and Durrington, P. N. (1991). Paraoxonase prevents accumulation of lipoperoxides in low-density lipoprotein. FEBS Lett. 286, 152-154. doi: 10.1016/0014-5793(91)80962-3

Mannic, T., Satta, N., Pagano, S., Python, M., Virzi, J., Montecucco, F., et al. (2015). CD14 as a mediator of the mineralocorticoid receptordependent anti-apolipoprotein A-1 IgG chronotropic effect on cardiomyocytes. Endocrinology 156, 4707-4719. doi: 10.1210/en.2015-1605

Martin, S. S., Khokhar, A. A., May, H. T., Kulkarni, K. R., Blaha, M. J., Joshi, P. H., et al. (2014). Hdl cholesterol subclasses, myocardial infarction, and mortality in secondary prevention: the Lipoprotein Investigators Collaborative. Eur. Heart J. 36, 22-30. doi: 10.1093/eurheartj/ehu264

Martínez-González, J., Escudero, I., and Badimon, L. (2004). Simvastatin potenciates PGI 2 release induced by HDL in human VSMC: effect on Cox-2 up-regulation and MAPK signalling pathways activated by HDL. Atherosclerosis 174, 305-313. doi: 10.1016/j.atherosclerosis.2004.01.037

Mathers, C. D., and Loncar, D. (2006). Projections of global mortality and burden of disease from 2002 to 2030. PLOS Med. 3:e442. doi: 10.1371/journal.pmed. 0030442

McKenney, J. M., Mccormick, L. S., Schaefer, E. J., Black, D. M., and Watkins, M. L. (2001). Effect of niacin and atorvastatin on lipoprotein subclasses in patients with atherogenic dyslipidemia. Am. J. Cardiol. 88, 270-274. doi: 10.1016/S00029149(01)01639-3

McMillen, T. S., Heinecke, J. W., and Leboeuf, R. C. (2005). Expression of human myeloperoxidase by macrophages promotes atherosclerosis in mice. Circulation 111, 2798-2804. doi: 10.1161/CIRCULATIONAHA.104.516278

Millar, J. S., and Cuchel, M. (2015). ApoA-I-directed therapies for the management of atherosclerosis. Curr. Atheroscler. Rep. 17, 1-7. doi: 10.1007/s11883-0150539-0

Mineo, C., and Shaul, P. W. (2003). HDL stimulation of endothelial nitric oxide synthase: a novel mechanism of HDL action. Trends Cardiovasc. Med. 13, 226-231. doi: 10.1016/S1050-1738(03)00098-7

Mitra, P., Oskeritzian, C. A., Payne, S. G., Beaven, M. A., Milstien, S., and Spiegel, S. (2006). Role of ABCC1 in export of sphingosine-1-phosphate from mast cells. Proc. Natl. Acad. Sci. U.S.A. 103, 16394-16399. doi: 10.1073/pnas.060373 4103

Montecucco, F., Braunersreuther, V., Burger, F., Lenglet, S., Pelli, G., Carbone, F., et al. (2015). Anti-apoA-1 auto-antibodies increase mouse atherosclerotic plaque vulnerability, myocardial necrosis and mortality triggering TLR2 and TLR4. Thromb. Haemost. 114, 410-422. doi: 10.1160/TH14-12-1039

Montecucco, F., Vuilleumier, N., Pagano, S., Lenglet, S., Bertolotto, M., Braunersreuther, V., et al. (2011). Anti-Apolipoprotein A-1 auto-antibodies are active mediators of atherosclerotic plaque vulnerability. Eur. Heart J. 32, 412-421. doi: 10.1093/eurheartj/ehq521

Moren, X., Lhomme, M., Bulla, A., Sanchez, J. C., Kontush, A., and James, R. W. (2016). Proteomic and lipidomic analyses of paraoxonase defined high density lipoprotein particles: association of paraoxonase with the anti-coagulant, protein S. Proteomics Clin. Appl. 10, 230-238. doi: 10.1002/prca.201500062

Morgan, J. M., Capuzzi, D. M., Baksh, R. I., Intenzo, C., Carey, C. M., Reese, D., et al. (2003). Effects of extended-release niacin on lipoprotein subclass distribution. Am. J. Cardiol. 91, 1432-1436. doi: 10.1016/S0002-9149(03) 00394- 1

Moutzouri, E., Kei, A., Elisaf, M. S., and Milionis, H. J. (2010). Management of dyslipidemias with fibrates, alone and in combination with statins: role of delayed-release fenofibric acid. Vasc. Health Risk Manag. 6, 525-539.

Musunuru, K., Orho-Melander, M., Caulfield, M. P., Li, S., Salameh, W. A., Reitz, R. E., et al. (2009). Ion mobility analysis of lipoprotein subfractions identifies three independent axes of cardiovascular risk. Arterioscler. Thromb. Vasc. Biol. 29, 1975-1980. doi: 10.1161/ATVBAHA.109.190405

Muthuramu, I., Amin, R., and De Geest, B. (2017). New Perspectives on Biological HDL-targeted Therapies. Abingdon: Taylor \& Francis. 
Nanjee, M., Doran, J., Lerch, P., and Miller, N. (1999). Acute effects of intravenous infusion of ApoA1/phosphatidylcholine discs on plasma lipoproteins in humans. Arterioscler. Thromb. Vasc. Biol. 19, 979-989. doi: 10.1161/01.ATV. 19.4.979

Nanjee, M. N., Cooke, J., Garvin, R., Semeria, F., Lewis, G., Olszewski, W. L., et al. (2001). Intravenous apoA-I/lecithin discs increase preb-HDL concentration in tissue fluid and stimulate reverse cholesterol transport in humans. J. Lipid Res. 42, 1586-1593

Navab, M., Hama, S. Y., Anantharamaiah, G., Hassan, K., Hough, G. P., Watson, A. D., et al. (2000). Normal high density lipoprotein inhibits three steps in the formation of mildly oxidized low density lipoprotein: steps 2 and 3. J. Lipid Res. 41, 1495-1508.

Neuman, M. P., Neuman, H. R., and Neuman, J. (1991). Significant increase of high-density lipoprotein 2-cholesterol under prolonged simvastatin treatment. Atherosclerosis 91, S11-S19. doi: 10.1016/0021-9150(91)90202-E

Nicholls, S. J., Ruotolo, G., Brewer, H. B., Kane, J. P., Wang, M.-D., Krueger, K. A., et al. (2015). Cholesterol efflux capacity and pre-beta-1 HDL concentrations are increased in dyslipidemic patients treated with evacetrapib. J. Am. Coll. Cardiol. 66, 2201-2210. doi: 10.1016/j.jacc.2015.09.013

Nieuwdorp, M., Vergeer, M., Bisoendial, R., op 't Roodt, J., Levels, H., Birjmohun, R., et al. (2008). Reconstituted HDL infusion restores endothelial function in patients with type 2 diabetes mellitus. Diabetologia 51, 1081-1084. doi: 10.1007/s00125-008-0975-2

Nissen, S. E., Tsunoda, T., Tuzcu, E. M., Schoenhagen, P., Cooper, C. J., Yasin, M., et al. (2003). Effect of recombinant ApoA-I Milano on coronary atherosclerosis in patients with acute coronary syndromes: a randomized controlled trial. JAMA 290, 2292-2300. doi: 10.1001/jama.290.17.2292

Nobécourt, E., Tabet, F., Lambert, G., Puranik, R., Bao, S., Yan, L., et al. (2010). Nonenzymatic glycation impairs the antiinflammatory properties of apolipoprotein AI. Arterioscler. Thromb. Vasc. Biol. 30, 766-772. doi: 10.1161/ ATVBAHA.109.201715

Nofer, J.-R., Van Der Giet, M., Tölle, M., Wolinska, I., Von Wnuck Lipinski, K., Baba, H. A., et al. (2004). HDL induces NO-dependent vasorelaxation via the lysophospholipid receptor S1P3. J. Clin. Invest. 113, 569-581. doi: 10.1172/ JCI200418004

O’Neill, F., Mcloughlin, E., Riwanto, M., Manz, J., Adler, A., Sutill, E., et al. (2015a). Reproducibility and biological variability of HDL'S vascular functional assays. Atherosclerosis 241, 588-594. doi: 10.1016/j.atherosclerosis.2015.06.005

O’Neill, F., Riwanto, M., Charakida, M., Colin, S., Manz, J., Mcloughlin, E., et al. (2015b). Structural and functional changes in HDL with low grade and chronic inflammation. Int. J. Cardiol. 188, 111-116. doi: 10.1016/j.ijcard.2015.03.058

Out, R., Hoekstra, M., Habets, K., Meurs, I., De Waard, V., Hildebrand, R. B., et al. (2008). Combined deletion of macrophage ABCA1 and ABCG1 leads to massive lipid accumulation in tissue macrophages and distinct atherosclerosis at relatively low plasma cholesterol levels. Arterioscler. Thromb. Vasc. Biol. 28, 258-264. doi: 10.1161/ATVBAHA.107.156935

Padró, T., Cubedo, J., Camino, S., Béjar, M. T., Ben-Aicha, S., Mendieta, G., et al. (2017). Detrimental effect of hypercholesterolemia on high-density lipoprotein particle remodeling in pigs. J. Am. Coll. Cardiol. 70, 165-178. doi: 10.1016/j. jacc.2017.05.018

Pagano, S., Carbone, F., Burger, F., Roth, A., Bertolotto, M., Pane, B., et al. (2016). Anti-apolipoprotein A-1 auto-antibodies as active modulators of atherothrombosis. Thromb. Haemost. 116, 554-564. doi: 10.1160/TH16-030229

Pagano, S., Gaertner, H., Cerini, F., Mannic, T., Satta, N., Teixeira, P. C., et al. (2015). The human autoantibody response to apolipoprotein AI is focused on the C-terminal helix: a new rationale for diagnosis and treatment of cardiovascular disease? PLOS ONE 10:e0132780. doi: 10.1371/journal.pone. 0132780

Pagano, S., Satta, N., Werling, D., Offord, V., De Moerloose, P., Charbonney, E., et al. (2012). Anti-apolipoprotein A-1 IgG in patients with myocardial infarction promotes inflammation through TLR2/CD14 complex. J. Intern. Med. 272, 344-357. doi: 10.1111/j.1365-2796.2012.02530.x

Parthasarathy, S., Barnett, J., and Fong, L. G. (1990). High-density lipoprotein inhibits the oxidative modification of low-density lipoprotein. Biochim. Biophys. Acta 1044, 275-283. doi: 10.1016/0005-2760(90)90314-N

Patel, S., Drew, B. G., Nakhla, S., Duffy, S. J., Murphy, A. J., Barter, P. J., et al. (2009). Reconstituted high-density lipoprotein increases plasma high-density lipoprotein anti-inflammatory properties and cholesterol efflux capacity in patients with type 2 diabetes. J. Am. Coll. Cardiol. 53, 962-971. doi: 10.1016/ j.jacc.2008.12.008

Piepoli, M. F., Hoes, A. W., Agewall, S., Albus, C., Brotons, C., Catapano, A. L., et al. (2016). 2016 European Guidelines on cardiovascular disease prevention in clinical practice The Sixth Joint Task Force of the European Society of Cardiology and Other Societies on Cardiovascular Disease Prevention in Clinical Practice (constituted by representatives of 10 societies and by invited experts) developed with the special contribution of the European Association for Cardiovascular Prevention \& Rehabilitation (EACPR). Eur. J. Prev. Cardiol. 37, 2315-2381.

Rader, D. J., Alexander, E. T., Weibel, G. L., Billheimer, J., and Rothblat, G. H. (2009). The role of reverse cholesterol transport in animals and humans and relationship to atherosclerosis. J. Lipid Res. 50, S189-S194. doi: 10.1194/jlr. R800088-JLR200

Riwanto, M., Rohrer, L., Roschitzki, B., Besler, C., Mocharla, P., Mueller, M., et al. (2013). Altered activation of endothelial anti-and pro-apoptotic pathways by high-density lipoprotein from patients with coronary artery disease: role of HDL-proteome remodeling. Circulation 127, 891-904. doi: 10.1161/ CIRCULATIONAHA.112.108753

Rodríguez, C., González-Díez, M., Badimon, L., and Martínez-González, J. (2009). Sphingosine-1-phosphate: a bioactive lipid that confers high-density lipoprotein with vasculoprotection mediated by nitric oxide and prostacyclin. Thromb. Haemost. 101, 665-673. doi: 10.1160/TH08-10-0675

Rohatgi, A., Khera, A., Berry, J. D., Givens, E. G., Ayers, C. R., Wedin, K. E., et al. (2014). HDL cholesterol efflux capacity and incident cardiovascular events. N. Engl. J. Med. 371, 2383-2393. doi: 10.1056/NEJMoa1409065

Rong, J. X., Li, J., Reis, E. D., Choudhury, R. P., Dansky, H. M., Elmalem, V. I., et al. (2001). Elevating high-density lipoprotein cholesterol in apolipoprotein E-deficient mice remodels advanced atherosclerotic lesions by decreasing macrophage and increasing smooth muscle cell content. Circulation 104, 24472452. doi: $10.1161 /$ hc4501.098952

Rosenson, R. S., Brewer, H. B. Jr., Ansell, B. J., Barter, P., Chapman, M. J., Heinecke, J. W., et al. (2016). Dysfunctional HDL and atherosclerotic cardiovascular disease. Nat. Rev. Cardiol. 13, 48-60. doi: 10.1038/nrcardio.2015.124

Rosenson, R. S., Brewer, H. B. Jr., Chapman, M. J., Fazio, S., Hussain, M. M. Kontush, A., et al. (2011). HDL measures, particle heterogeneity, proposed nomenclature, and relation to atherosclerotic cardiovascular events. Clin. Chem. 57, 392-410. doi: 10.1373/clinchem.2010.155333

Ruotolo, G., Ericsson, C.-G., Tettamanti, C., Karpe, F., Grip, L., Svane, B., et al. (1998). Treatment effects on serum lipoprotein lipids, apolipoproteins and low density lipoprotein particle size and relationships of lipoprotein variables to progression of coronary artery disease in the Bezafibrate Coronary Atherosclerosis Intervention Trial (BECAIT). J. Am. Coll. Cardiol. 32, 16481656. doi: 10.1016/S0735-1097(98)00442-2

Rye, K. A., and Barter, P. J. (2014). Regulation of high-density lipoprotein metabolism. Circ. Res. 114, 143-156. doi: 10.1161/CIRCRESAHA.114. 300632

Salazar, J., Olivar, L. C., Ramos, E., Chávez-Castillo, M., Rojas, J., and Bermúdez, V. (2015). Dysfunctional high-density lipoprotein: an innovative target for proteomics and lipidomics. Cholesterol 2015:296417. doi: 10.1155/2015/ 296417

Saleheen, D., Scott, R., Javad, S., Zhao, W., Rodrigues, A., Picataggi, A., et al. (2015). Association of HDL cholesterol efflux capacity with incident coronary heart disease events: a prospective case-control study. Lancet Diabetes Endocrinol. 3, 507-513. doi: 10.1016/S2213-8587(15)00126-6

Sattler, K., Gräler, M., Keul, P., Weske, S., Reimann, C.-M., Jindrová, H., et al. (2015). Defects of high-density lipoproteins in coronary artery disease caused by low sphingosine-1-phosphate content: correction by sphingosine1-phosphate-loading. J. Am. Coll. Cardiol. 66, 1470-1485. doi: 10.1016/j.jacc. 2015.07.057

Sattler, K. J., Elbasan, Ş., Keul, P., Elter-Schulz, M., Bode, C., Gräler, M. H., et al. (2010). Sphingosine 1-phosphate levels in plasma and HDL are altered in coronary artery disease. Basic Res. Cardiol. 105, 821-832. doi: 10.1007/s00395010-0112-5

Schwartz, G. G., Olsson, A. G., Abt, M., Ballantyne, C. M., Barter, P. J., Brumm, J., et al. (2012). Effects of dalcetrapib in patients with a recent acute coronary syndrome. N. Engl. J. Med. 367, 2089-2099. doi: 10.1056/NEJMoa1206797 
Serban, C., Muntean, D., Mikhailids, D. P., Toth, P. P., and Banach, M. (2014). Dysfunctional HDL: the journey from savior to slayer. Clin. Lipidol. 9, 49-59. doi: $10.2217 / \mathrm{clp} .13 .83$

Serna, J., García-Seisdedos, D., Alcázar, A., Lasunción, M. Á., Busto, R., and Pastor, Ó. (2015). Quantitative lipidomic analysis of plasma and plasma lipoproteins using Maldi-Tof mass spectrometry. Chem. Phys. Lipids 189, 7-18. doi: 10.1016/ j.chemphyslip.2015.05.005

Shamburek, R. D., Bakker-Arkema, R., Shamburek, A. M., Freeman, L. A., Amar, M. J., Auerbach, B., et al. (2016). Safety and tolerability of ACP-501, a recombinant human lecithin:cholesterol acyltransferase, in a phase 1 singledose escalation study. Circ. Res. 118, 73-82. doi: 10.1161/CIRCRESAHA.115. 306223

Shaw, J. A., Bobik, A., Murphy, A., Kanellakis, P., Blombery, P., Mukhamedova, N., et al. (2008). Infusion of reconstituted high-density lipoprotein leads to acute changes in human atherosclerotic plaque. Circ. Res. 103, 1084-1091. doi: 10.1161/CIRCRESAHA.108.182063

Shuhei, N., Söderlund, S., Jauhiainen, M., and Taskinen, M.-R. (2010). Effect of HDL composition and particle size on the resistance of Hdl to the oxidation. Lipids Health Dis. 9:104. doi: 10.1186/1476-511X-9-104

Simic, B., Mocharla, P., Crucet, M., Osto, E., Kratzer, A., Stivala, S., et al. (2017). Anacetrapib, but not evacetrapib, impairs endothelial function in CETP-transgenic mice in spite of marked HDL-C increase. Atherosclerosis 257, 186-194. doi: 10.1016/j.atherosclerosis.2017.01.011

Soedamah-Muthu, S., Colhoun, H., Thomason, M., Betteridge, D., Durrington, P., Hitman, G., et al. (2003). The effect of atorvastatin on serum lipids, lipoproteins and $\mathrm{Nmr}$ spectroscopy defined lipoprotein subclasses in type 2 diabetic patients with ischaemic heart disease. Atherosclerosis 167, 243-255. doi: 10.1016/S00219150(02)00428-8

Song, W., Wang, W., Dou, L.-Y., Wang, Y., Xu, Y., Chen, L.-F., et al. (2015). The implication of cigarette smoking and cessation on macrophage cholesterol efflux in coronary artery disease patients. J. Lipid Res. 56, 682-691. doi: 10.1194/ jlr.P055491

Staels, B., Dallongeville, J., Auwerx, J., Schoonjans, K., Leitersdorf, E., and Fruchart, J.-C. (1998). Mechanism of action of fibrates on lipid and lipoprotein metabolism. Circulation 98, 2088-2093. doi: 10.1161/01.CIR.98. 19.2088

Stafforini, D. M., Mcintyre, T. M., Carter, M., and Prescott, S. (1987). Human plasma platelet-activating factor acetylhydrolase. Association with lipoprotein particles and role in the degradation of platelet-activating factor. J. Biol. Chem. $262,4215-4222$.

Sun, J. T., Yang, K., Lu, L., Zhu, Z. B., Zhu, J. Z., Ni, J. W., et al. (2016). Increased carbamylation level of HDL in end-stage renal disease: carbamylatedHDL attenuated endothelial cell function. Am. J. Physiol. Renal Physiol. 310, F511-F517. doi: 10.1152/ajprenal.00508.2015

Superko, H. R., Garrett, B. C., King, S. B. III., Momary, K. M., Chronos, N. A., and Wood, P. D. (2009). Effect of combination nicotinic acid and gemfibrozil treatment on intermediate density lipoprotein, and subclasses of low density lipoprotein and high density lipoprotein in patients with combined hyperlipidemia. Am. J. Cardiol. 103, 387-392. doi: 10.1016/j.amjcard.2008. 09.103

Tall, A. R., Yvan-Charvet, L., Terasaka, N., Pagler, T., and Wang, N. (2008). HDL, ABC transporters, and cholesterol efflux: implications for the treatment of atherosclerosis. Cell Metab. 7, 365-375. doi: 10.1016/j.cmet.2008. 03.001

Tardif, J.-C., Ballantyne, C. M., Barter, P., Dasseux, J.-L., Fayad, Z. A., Guertin, M.-C., et al. (2014). Effects of the high-density lipoprotein mimetic agent CEr001 on coronary atherosclerosis in patients with acute coronary syndromes: a randomized trial. Eur. Heart J. 35, 3277-3286. doi: 10.1093/eurheartj/ ehu171

Tardif, J.-C., Grégoire, J., L’allier, P. L., Ibrahim, R., Lespérance, J., Heinonen, T. M., et al. (2007). Effects of reconstituted high-density lipoprotein infusions on coronary atherosclerosis: a randomized controlled trial. JAMA 297, 1675-1682. doi: 10.1001/jama.297.15.jpc70004

Theilmeier, G., Schmidt, C., Herrmann, J., Keul, P., Schäfers, M., Herrgott, I., et al. (2006). High-density lipoproteins and their constituent, sphingosine1-phosphate, directly protect the heart against ischemia/reperfusion injury in vivo via the S1P 3 lysophospholipid receptor. Circulation 114, 1403-1409. doi: 10.1161/CIRCULATIONAHA.105.607135
Tian, L., Li, C., Liu, Y., Chen, Y., and Fu, M. (2014). The value and distribution of high-density lipoprotein subclass in patients with acute coronary syndrome. PLOS ONE 9:e85114. doi: 10.1371/journal.pone.0085114

Toth, P. P., Thakker, K. M., Jiang, P., and Padley, R. J. (2012). Niacin extended-release/simvastatin combination therapy produces larger favorable changes in high-density lipoprotein particles than atorvastatin monotherapy. Vasc. Health Risk Manag. 8, 39-44. doi: 10.2147/VHRM. S22601

Vaisar, T., Pennathur, S., Green, P. S., Gharib, S. A., Hoofnagle, A. N., Cheung, M. C., et al. (2007). Shotgun proteomics implicates protease inhibition and complement activation in the antiinflammatory properties of HDL. J. Clin. Invest. 117, 746-756. doi: 10.1172/JCI26206

Van Craeyveld, E., Gordts, S. C., Nefyodova, E., Jacobs, F., and De Geest, B. (2011). Regression and stabilization of advanced murine atherosclerotic lesions: a comparison of LDL lowering and HDL raising gene transfer strategies. J. Mol. Med. 89, 555-567. doi: 10.1007/s00109-011-0722-x

van der Steeg, W. A., Holme, I., Boekholdt, S. M., Larsen, M. L., Lindahl, C., Stroes, E. S., et al. (2008). High-density lipoprotein cholesterol, high-density lipoprotein particle size, and apolipoprotein AI: significance for cardiovascular risk: the IDEAL and EPIC-Norfolk studies. J. Am. Coll. Cardiol. 51, 634-642. doi: 10.1016/j.jacc.2007.09.060

Van Lenten, B. J., Hama, S. Y., De Beer, F. C., Stafforini, D. M., Mcintyre, T. M., Prescott, S. M., et al. (1995). Anti-inflammatory HDL becomes proinflammatory during the acute phase response. Loss of protective effect of HDL against LDL oxidation in aortic wall cell cocultures. J. Clin. Invest. 96, 2758.

Vaziri, N. D. (2015). HDL abnormalities in nephrotic syndrome and chronic kidney disease. Nat. Rev. Nephrol. 12, 37-47. doi: 10.1038/nrneph.2015.180

Verdoia, M., Schaffer, A., Suryapranata, H., and De Luca, G. (2015). Effects of HDL-modifiers on cardiovascular outcomes: a meta-analysis of randomized trials. Nutr. Metab. Cardiovasc. Dis. 25, 9-23. doi: 10.1016/j.numecd.2014. 09.003

Vilahur, G., Gutiérrez, M., Casaní, L., Cubedo, J., Capdevila, A., Pons-Llado, G., et al. (2015). Hypercholesterolemia abolishes high-density lipoprotein-related cardioprotective effects in the setting of myocardial infarction. J. Am. Coll. Cardiol. 66, 2469-2470. doi: 10.1016/j.jacc.2015.08.901

Vinals, M., Martinez-Gonzalez, J., Badimon, J., and Badimon, L. (1997). HDL-induced prostacyclin release in smooth muscle cells is dependent on cyclooxygenase-2 (Cox-2). Arterioscler. Thromb. Vasc. Biol. 17, 3481-3488. doi: 10.1161/01.ATV.17.12.3481

Viñals, M., Martínez-González, J., and Badimon, L. (1999). Regulatory effects of HDL on smooth muscle cell prostacyclin release. Arterioscler. Thromb. Vasc. Biol. 19, 2405-2411. doi: 10.1161/01.ATV.19.10.2405

Vu-Dac, N., Schoonjans, K., Kosykh, V., Dallongeville, J., Fruchart, J.-C., Staels, B., et al. (1995). Fibrates increase human apolipoprotein A-II expression through activation of the peroxisome proliferator-activated receptor. J. Clin. Invest. 96, 741-750. doi: 10.1172/JCI118118

Vuilleumier, N., Bas, S., Pagano, S., Montecucco, F., Guerne, P. A., Finckh, A., et al. (2010a). Anti-apolipoprotein A-1 IgG predicts major cardiovascular events in patients with rheumatoid arthritis. Arthritis Rheumatol. 62, 2640-2650. doi: 10.1002/art.27546

Vuilleumier, N., Montecucco, F., Spinella, G., Pagano, S., Bertolotto, M., Pane, B., et al. (2013). Serum levels of anti-apolipoprotein A-1 auto-antibodies and myeloperoxidase as predictors of major adverse cardiovascular events after carotid endarterectomy. Thromb. Haemost. 109, 706-715. doi: 10.1160/TH1210-0714

Vuilleumier, N., Rossier, M. F., Pagano, S., Python, M., Charbonney, E., Nkoulou, R., et al. (2010b). Anti-apolipoprotein A-1 IgG as an independent cardiovascular prognostic marker affecting basal heart rate in myocardial infarction. Eur. Heart J. 31, 815-823. doi: 10.1093/eurheartj/ehq055

Wheeler, J. G., Keavney, B. D., Watkins, H., Collins, R., and Danesh, J. (2004). Four paraoxonase gene polymorphisms in 11212 cases of coronary heart disease and 12786 controls: meta-analysis of 43 studies. Lancet 363, 689-695. doi: 10.1016/S0140-6736(04)15642-0

Wiesner, P., Leidl, K., Boettcher, A., Schmitz, G., and Liebisch, G. (2009). Lipid profiling of FPLC-separated lipoprotein fractions by electrospray ionization tandem mass spectrometry. J. Lipid Res. 50, 574-585. doi: 10.1194/jlr.D800028JLR200 
Woudberg, N. J., Goedecke, J. H., Blackhurst, D., Frias, M., James, R., Opie, L. H., et al. (2016). Association between ethnicity and obesity with high-density lipoprotein (HDL) function and subclass distribution. Lipids Health Dis. 15:92. doi: 10.1186/s12944-016-0257-9

Yu, J., Han, J.-L., He, L.-Y., Feng, X.-H., Li, W.-H., Mao, J.-M., et al. (2013). Low density lipoprotein cholesterol level inversely correlated with coronary flow velocity reserve in patients with Type 2 diabetes. J. Geriatr. Cardiol. 10, 159-164. doi: 10.3969/j.issn.1671-5411.2013.02.007

Yu, X. H., Fu, Y. C., Zhang, D. W., Yin, K., and Tang, C. K. (2013). Foam cells in atherosclerosis. Clin. Chim. Acta 424, 245-252. doi: 10.1016/j.cca.2013.06.006

Yuhanna, I. S., Zhu, Y., Cox, B. E., Hahner, L. D., Osborne-Lawrence, S., Lu, P., et al. (2001). High-density lipoprotein binding to scavenger receptor-BI activates endothelial nitric oxide synthase. Nat. Med. 7, 853-857. doi: 10.1038/89986

Yvan-Charvet, L., Ranalletta, M., Wang, N., Han, S., Terasaka, N., Li, R., et al. (2007). Combined deficiency of ABCA1 and ABCG1 promotes foam cell accumulation and accelerates atherosclerosis in mice. J. Clin. Invest. 117, 3900-3908. doi: 10.1172/JCI33372

Zewinger, S., Drechsler, C., Kleber, M. E., Dressel, A., Riffel, J., Triem, S., et al. (2015). Serum amyloid A: high-density lipoproteins interaction and cardiovascular risk. Eur. Heart J. 36, 3007-3016. doi: 10.1093/eurheartj/ehv352
Zheng, K. H., Van Der Valk, F. M., Smits, L. P., Sandberg, M., Dasseux, J.-L., Baron, R., et al. (2016). HDL mimetic CER-001 targets atherosclerotic plaques in patients. Atherosclerosis 251, 381-388. doi: 10.1016/j.atherosclerosis.2016. 05.038

Conflict of Interest Statement: RS reports personal fees from Amgen, personal fees from Recordati, grants and personal fees from Sanofi, outside the submitted work.

The other authors declare that the research was conducted in the absence of any commercial or financial relationships that could be construed as a potential conflict of interest.

Copyright (c) 2018 Woudberg, Pedretti, Lecour, Schulz, Vuilleumier, James and Frias. This is an open-access article distributed under the terms of the Creative Commons Attribution License (CC BY). The use, distribution or reproduction in other forums is permitted, provided the original author(s) or licensor are credited and that the original publication in this journal is cited, in accordance with accepted academic practice. No use, distribution or reproduction is permitted which does not comply with these terms. 